\title{
The Time Course of Grief Reactions to Spousal Loss: Evidence From a National Probability Sample
}

\author{
Katherine B. Carnelley \\ University of Southampton
}

\author{
Niall Bolger \\ Columbia University
}

\author{
Camille B. Wortman \\ Stony Brook University, State University of New York
}

Christopher T. Burke
New York University

\begin{abstract}
Most studies of widowhood have focused on reactions during the first few years postloss. The authors investigated whether widowhood had more enduring effects using a nationally representative U.S. sample. Participants were 768 individuals who had lost their spouse (from a few months to 64 years) prior to data collection. Results indicated that the widowed continued to talk, think, and feel emotions about their lost spouse decades later. Twenty years postloss, the widowed thought about their spouse once every week or 2 and had a conversation about their spouse once a month on average. About 12.6 years postloss, the widowed reported feeling upset between sometimes and rarely when they thought about their spouse. These findings add to an understanding of the time course of grief.
\end{abstract}

Keywords: bereavement, widowhood, continuing bonds, meaning, positive growth

Loss of a spouse is one of the most serious threats to health, well-being, and productivity that most people encounter during their lives (see M. S. Stroebe, Hansson, Stroebe, \& Schut, 2001b, for a review), although there is considerable variability in responses to loss (e.g., Bonanno et al., 2002). Much research has investigated the impact of widowhood during the first few years postloss (e.g., Carnelley, Wortman, \& Kessler, 1999); however, very little research has examined the long-term outcomes (positive and negative) and long-term processes (resolution and continuing involvement) associated with spousal loss. Indeed, M. S. Stroebe, Hansson, Stroebe, and Schut (2001a) called for research to examine the time course of grief reactions. The present study investigated the time course of grief reactions to spousal loss in a nationally representative U.S. sample using Wave 1 of the Americans' Changing Lives (ACL) data set (House et al., 1990).

Although many theorists have described the process through which individuals come to terms with the loss of a spouse, their

Katherine B. Carnelley, School of Psychology, University of Southampton, Highfield, Southampton, United Kingdom; Camille B. Wortman, Department of Psychology, Stony Brook University, State University of New York; Niall Bolger, Department of Psychology, Columbia University; Christopher T. Burke, Department of Psychology, New York University.

This research was conducted at the Survey Research Center at the Institute for Social Research, University of Michigan, Ann Arbor, Michigan, and was supported by National Institute on Aging Grant R01 A610757 (Camille B. Wortman, principal investigator; Ronald C. Kessler, coprincipal investigator), by Training Grant T32 MH16806 (Ronald C. Kessler, principal investigator), and by Research Scientist Development Award 1 K02 MH99507 to Ronald C. Kessler from the National Institute of Mental Health. We thank Ronald C. Kessler for guidance with the analysis strategy.

Correspondence concerning this article should be addressed to Katherine B. Carnelley, School of Psychology, University of Southampton, Highfield, Southampton SO17 1BJ, United Kingdom. E-mail: KC6@soton.ac.uk theories say little about the time course of grief reactions. Some bereavement theorists have suggested that the bereaved go through a series of stages or phases (see Aiken, 1991, for a review); Bowlby (1980), for example, proposed four phases: shock, yearning and protest, despair, and recovery. Bereavement researchers do not currently view phases of grief as fixed and sequential (Archer, 1999; M. S. Stroebe et al., 2001a). As thoughts and memories of the deceased are reviewed, the individual is believed to work through the implications of the loss (Rando, 1993; Worden, 2002). The notion that grief must be worked through has been the dominant perspective for the past century (Bonanno et al., 2002). However, the assumption that emotions need to be worked through has been questioned more recently (e.g., M. S. Stroebe \& Stroebe, 1991). At this point, the bereaved is expected to reach a state of acceptance (Gorer, 1967; Hardt, 1978-1979), reorganization of the mental representation of the lost person (Bowlby, 1980), or recovery (Glick, Weiss, \& Parkes, 1974; Stephenson, 1985). Although many theorists have portrayed the grief process in several ways and there are debates about how it unfolds, none have described the time course of grief. They have not addressed how long it takes to go through stages or phases, work through grief, resolve what has happened, or recover. Indeed, bereavement researchers have begun to question the notion of recovery (e.g., Miller \& Omarzu, 1998; M. S. Stroebe, Hansson, Stroebe, \& Schut, 2001c), suggesting that "in the long-term, the bereaved do not simply 'return to baseline' following the loss" (M. S. Stroebe et al., 2001a, p. 746).

In what follows, we summarize relevant past research that has focused on the bereaved individual's continuing cognitive and emotional involvement with the lost person and eventual resolution of the loss. In addition, we discuss research suggesting that sometimes personal growth is an outcome of spousal loss. Finally, we present data from our cross-sectional, large- 
scale, national study to examine the time course of widowhood grief reactions.

\section{Continuing Involvement and Emotional Resolution}

Bereaved individuals often feel a bond with the deceased that can continue for decades (e.g., Shaver \& Tancredy, 2001). This continuing sense of connection does not necessarily indicate poor adjustment to loss (Bonanno, Wortman, \& Nesse, 2004; Klass, Silverman, \& Nickman, 1996). Although there are various types of continuing involvement, our review primarily focuses on those investigated in the present study: memories and conversations about the deceased and anniversary reactions.

Memories of a lost spouse may simultaneously bring comfort and cause distress. Shaver and Tancredy's (2001) discussion of contemporary emotion theory (e.g., Frijda, 1986, 1988; Lazarus, 1991, 1999) and attachment theory (Bowlby, 1969, 1973, 1980; Cassidy \& Shaver, 1999) helps one to understand the relationship between memories and emotions. The bereaved hold many affectively charged representations of the lost spouse and of the spouse in interaction with the self. A priming of one of these memories activates emotions that are difficult to ignore.

Grieving is partly a matter of bumping up against these thoughts and feelings over a period of months or years and acknowledging both their affective charge and their inadequacy as representations of current reality. They have to be reworked ... or weakened by habituation. (Shaver \& Tancredy, 2001, p. 72)

Weiss (2001) stated that it is the persistence of these affectively charged representations of the attachment figure (spouse) that enable the bereaved to feel a continued connection with the deceased.

Although many theorists have maintained that over time, the bereaved person's memories are worked through so that they are no longer painful (Parkes \& Weiss, 1983; Rando, 1993; Worden, 2002), more recently, bereavement researchers have begun to question this assumption (e.g., M. S. Stroebe \& Stroebe, 1991). Hence, it is important to assess emotional resolution (Weiss, 1988), or how long the bereaved continue to experience emotional pain when they think or talk about their spouse or when they encounter reminders. Although they did not assess whether or not memories were painful, Bonanno et al. (2004) did examine how typical it was for different types of grievers to think about their lost spouse over time. Their results showed that thinking about one's spouse from 6 to 18 months postloss is quite common (at 6 months, such thoughts ranged from daily or almost daily to several times a day, and at 18 months, they ranged from approximately 4 times a week to between daily and several times a day). Their findings also suggest that those who think about their spouse the most show worse adjustment to loss; this may be due to rumination. Research needs to examine the extent to which these thoughts are negative or positive and comforting.

An important question concerns the role of positive memories of one's spouse in adjustment to loss. Do positive memories increase over time as a person comes to terms with the loss, or do they decrease over time as the loss becomes less salient to the widowed spouse? Field, Nichols, Holen, and Horowitz (1999) examined the consequences of continuing involvement in the form of fond memories on distress levels in a monologue role-playing with one's deceased spouse 6 months postloss. They found that those participants who frequently felt comforted from memories of their spouse showed less grief severity and less helplessness about coping with the loss in the role-playing. Consistent with this, Bonanno et al. (2004) found that at 6 and 18 months postloss, receiving comfort from positive memories of one's spouse was most characteristic of the better functioning bereaved. However, in contrast, Field, Gal-Oz, and Bonanno (2003) examined the effects of fond memories about the deceased on grief 5 years postloss and found that having many fond memories was correlated with more grief but uncorrelated with depression, the Symptom Checklist (Derogatis, 1983), and positive states of mind. Taken together, these results suggest that fond memories may be more beneficial shortly after the loss than several years postloss; people who have many fond memories of their spouse 5 years postloss may also be inclined to ruminate about the loss and experience mental anguish.

Continuing involvement via conversation with others and its impact on grief reactions are understudied (Klass \& Walter, 2001). An exception is work by Bonanno et al. (2004), who found that at 6 months postloss, the bereaved talked about their spouse from once a week to two or three times a week; at 18 months postloss, they talked about their spouse about once a week. This shows that the widowed talk about their spouse fairly often up to 18 months postloss. The present study examined the frequency of conversations, memories, and emotional resolution over time and their rate of change over time in the long-term adjustment to loss.

Another goal of the study was to learn more about anniversary reactions following conjugal loss. Anniversary reactions are periods of acute grief triggered by occasions associated with the deceased (e.g., date of death or birthday). It has been argued that such reactions are often quite intense even several years after the loss (see Rando, 1993, for a detailed discussion). Although there are few relevant studies, they have suggested that such reactions are quite common. In a study of people who lost a loved one anywhere from one month to 22 years previously, Zisook, Devaul, and Click (1982) found that $25 \%$ of the respondents reported being upset at the anniversary of the death. A major aim of the present study has been to provide more information about the prevalence of anniversary reactions over time. We examined the frequency, intensity, and duration of anniversary reactions and their rate of change over time.

\section{Finding Meaning in the Loss}

One reason why the loss of a spouse can have such a powerful impact on well-being is that it can deprive the bereaved person's life of meaning (Marris, 1958). Janoff-Bulman (1992) argued that individuals have three core assumptions to their inner world: (a) They are worthy, (b) the world is benevolent, and (c) what happens to them makes sense. The death of a spouse can shatter these assumptions, leaving the individual to rebuild his or her assumptive world and reestablish meaning. Janoff-Bulman and Frantz (1997) and Davis, Nolen-Hoeksema, and Larson (1998) discussed two types of meaning that can be found in a loss: (a) making sense of the event and (b) finding value or benefit in the experience. Parkes and Weiss (1983) found that 2 to 4 years later, $61 \%$ of suddenly bereaved individuals and $29 \%$ of forewarned bereaved individuals were still questioning why the death had happened. Not surprisingly, it is easier to make sense of a natural death than a 
sudden death. For example, Lehman, Wortman, and Williams (1987) found that of those who lost their spouse in a car accident, $68 \%$ had not found meaning in the loss 4-7 years later. In contrast, in a sample of elderly, conjugally bereaved individuals whose spouses died of various causes (Bonanno et al., 2004), most did not search for meaning (71\% 6 months postloss and 72\% 18 months postloss). They found that $14 \%$ of the widowed searched for but did not find meaning in the loss at 6 and 18 months postloss, and $15 \%$ and $13 \%$ searched for and found meaning at 6 months and 18 months postloss, respectively. Interestingly, Davis and NolenHoeksema (2001) found that bereaved who had difficulty making sense of the loss at 6 months postloss also tended to have difficulty making sense of it later (at 18 months). In addition, those who make sense of it later for the first time provide explanations that are not comforting (i.e., the world is not a just, ordered, or benevolent place).

Research has suggested that being able to find positive meaning in a loss leads to better adjustment. Davis et al. (1998) found that making sense of the loss of a family member at 6 months postloss was associated with less distress at 6 and 13 months postloss but not associated with distress at 18 months postloss. In addition, finding benefit in the loss was associated with adjustment at 6,13 , and 18 months postloss. However, their results suggest that finding meaning leads to better adjustment primarily when meaning is found relatively shortly after the death. Specifically, making sense of the loss by 6 months postloss was associated with less distress; however, making sense of the loss for the first time at a later date was not associated with distress.

Finally, some research has suggested that those who adjust best do not search for meaning. Davis, Wortman, Lehman, and Silver (2000) found in a sample of adults who lost a spouse or child in a car accident that those who never searched for meaning showed better adjustment than those searching but not finding meaning; those who found meaning did not differ significantly from either group, but their scores fell between the other two groups. Similarly, Bonanno et al. (2004) found that not searching for meaning was most typical of their resilient grievers at 6 and 18 months postloss, whereas searching for and finding meaning at 18 months was most typical of their chronic grievers. Taken together, these results suggest that two groups of the bereaved show the least distress: (a) those who never search for meaning and (b) those who search for meaning, make sense of the death early, and are able to hold onto that meaning over time. The present study investigated the cognitive resolution of loss over a longer time frame, including searching for meaning, whether meaning was found, and the kinds of meanings found.

\section{Personal Growth}

Although widowhood can have profound negative effects, there is also some evidence suggesting that it may ultimately lead to psychological growth (e.g., Schaefer \& Moos, 2001; Wortman \& Silver, 1990). As a result of the loss, the bereaved person may learn a new set of skills that can result in positive changes, such as enhanced self-competence (e.g., Lopata, 1973). Some studies have shown that the widowed report increased personal growth and the discovery of new strengths, more independence, control, competence, resilience, self-assurance, and self-efficacy (Arbuckle \& de Vries, 1995; Calhoun \& Tedeschi, 1990; Fry, 1998; Lieberman,
1996; Thomas, DiGiulio, \& Sheehan, 1988). These studies have shown reports of growth 1 to 15 years after the loss. In addition, Bonanno et al. (2004) showed that perceived benefits of loss increase from 6 months to 18 months postloss. In the present study, we examined levels of positive change over a much longer period of time, focusing on perceptions of increased self-confidence and personal growth.

\section{The Present Study}

The present study has several methodological strengths that improve on much of the prior research. First, it was based on a large, nationally representative sample of 768 men and women who lost their spouse. The response rate, $67 \%$, although not ideal, is higher than most previous bereavement studies (e.g., Parkes \& Weiss, 1983). Second, our study incorporated a wide range of measures of reactions to loss over time, including key process and outcome measures identified in prior research. Third, the study is one of the few to help clarify how people typically experience grief reactions many years after the loss. Fourth, respondents were not recruited for a study of bereavement but rather for a study on productivity, stress, and health. There is evidence to suggest that willingness to participate in studies of bereavement is affected by the respondent's level of depression and other psychological variables (M. S. Stroebe \& Stroebe, 1989), making it difficult to draw inferences about the impact of conjugal loss. Because the study was not described as a study of bereavement and because most respondents were approached a considerable period of time after the loss, such selection problems are less likely to have occurred.

Finally, the study helps to clarify what form adjustment to loss takes. Is there a great deal of change during the first few months or years after the loss, followed by a period of more gradual change, or is there a steady change as time unfolds? An important consideration in our analysis is the functional relationship between time since widowhood and measures of adjustment. Theories of self-regulation, such as that of Carver and Scheier (1982), suggest that self-regulatory (or adjustment) behavior in people can be usefully described using a negative feedback model that (for our purposes) has three key features. First, regulatory systems can be driven out of equilibrium by external forces, just as a person would be driven out of psychological equilibrium by the passing of his or her spouse. Second, regulatory systems often involve negative feedback loops and move toward some equilibrium or end state, just as a person who has been widowed usually moves toward a state of recovery or psychological equilibrium. Third, when in a state of disequilibrium, people engage in regulatory behaviors to reduce perceived discrepancies between their current state and the end or goal state. The magnitude of the regulatory behavior should then depend on the magnitude of the perceived discrepancy, with larger discrepancies leading to stronger regulatory behaviors.

If this model accurately represents the process of adjustment to widowhood, then a simple linear model cannot describe the relationship between time since widowhood and an individual's level of adjustment. Rather, we would expect that change would be relatively rapid initially and would decelerate as it approached an equilibrium level. Estimating such a model can be accomplished by specifying the specific functional form of the relationship and using nonlinear regression methods (Rawlings, Pantula, \& Dickey, 1998; Singer \& Willett, 2003). A wide range of biological systems 
and processes seem to involve negative feedback systems such as this (McGuigan, 1994), and a negative exponential (or exponential decay) function has often been used to describe this movement toward equilibrium (Singer \& Willett, 2003). Thus, we believe that this function better explains the pattern of adjustment as a function of time than a simple linear model.

There are, however, two complications that arose in our study with respect to this approach. First, because our data were crosssectional, we could not directly observe within-person change but could only observe differences between persons who differed in time since widowhood. Thus, it was important to measure and adjust for influences that could produce spurious differences in adjustment and affect the shape of the adjustment function, as in the case in which those who lost spouses more recently had losses that were less unexpected or less sudden than those in previous decades. Furthermore, there is the issue of heterogeneity in adjustment processes. As Bonanno and his colleagues (2002) have shown, not all people experience bereavement in the same way. Given that the variables measured in our study are in many cases novel assessments of grief processes, we have chosen to focus on overall patterns across a broad range of adjustment measures, on the assumption that future, more focused studies would explore heterogeneity in grief processes.

In sum, our overall goal was to assess how quickly and completely people adjust to the loss of their spouse and to provide guideposts validated by research data indicating what typical grieving is. The research was designed to address a number of specific questions. Drawing on comparisons of participants who differed in time since bereavement, what would the shape of the time-since-loss function be, and more specifically, how would the implied rate of change vary depending on the length of time since the loss? Would the function imply that there was a great deal of adjustment in the first few months or years after the loss, followed by a period of slower or more gradual change (i.e., negative exponential), or would there be a steady change as time increased (i.e., linear)? Would it be typical for a bereaved person to think or talk about the spouse 10,20 , or 30 years after the loss, or would such thoughts occur infrequently by the end of the first decade? How long would it be typical to experience painful or fond memories? Would those who experienced conjugal loss show evidence of positive psychological change? Answers to these questions should not only clarify the nature and duration of bereavement processes for a nationally representative sample of the U.S. population but also enhance the ability to intervene effectively to promote better adjustment.

\section{Method}

\section{Participants}

Participants were drawn from a nationally representative sample of U.S. adults who were interviewed as part of a large-scale study of productivity, stress, and health in middle and late life. This study, the ACL study mentioned above, was conducted by the Survey Research Center at the University of Michigan (for more information about the ACL study, see House et al., 1990). The study involved face-to-face interviews with a multistage, stratified probability sample of noninstitutionalized persons 25 years of age or older and living in the continental United States. To obtain enough older and Black respondents to permit analysis by subgroups and to maximize the number of widowed respondents who would be inter- viewed, Blacks and respondents over 60 years old were sampled at twice the rate of Whites under 60. The final sample included a total of 3,617 respondents, reflecting an overall response rate of $67 \%$. As is usual in survey research, in analyses to be reported here, the data were weighted to adjust for variations in probabilities of selection and in response rates across sampling areas (see Kalton \& Flores-Cervantes, 2003, and Lessler \& Kalsbeek, 1992, for more detail on survey weighting procedures). In addition, poststratification weights were added to make the weighted sample correspond to the July 1985 Current Population Survey (United States Bureau of the Census, 1985) estimates by sex, age (25-64 years old and $65+$ years old), and region (Northeast, Midwest, South, and West). Interviews were conducted with 3,212 persons who had ever been married; $786^{1}$ of these persons ( 155 men and 631 women) had experienced the death of their spouse prior to the interview anywhere from less than 1 to 64 years previously. To give a better sense of how the number of years respondents had been widowed was distributed, the lower quartile was 0 to 5 years, the second quartile was 5 to 11 years, the third quartile was 11 to 21 years, and the fourth quartile was 21 to 64 years.

The data were collected between May and December of 1986, and the interview averaged 86 minutes in length. All respondents were asked questions about their health, well-being, productive activities, stressful life experiences, and coping resources. In addition, people who had lost a spouse were asked about the circumstances surrounding the loss and their current thoughts and feelings about the loss. It was felt that answering questions that focused on the loss (e.g., frequency of memories) might be too upsetting for those who were recently widowed, and for this reason, respondents widowed in the past 3 months $(n=15)$ were not asked these questions. An additional 3 respondents were missing data on the variable indicating whether the death had been unexpected. Thus, the effective $n$ for all analyses (unless otherwise noted) was 768 .

\section{Measures}

Our analyses focused on measures of bereaved respondents' current assessments of their emotional recovery, including the nature and frequency of thoughts and memories of the deceased, emotional and cognitive resolution of the loss, and perceptions of positive change. To facilitate comparisons among the measures, we followed the recommendations of Cohen, Cohen, Aiken, and West (1999) and rescaled all dependent variables such that the lowest possible score was 0 and the highest possible score was 100. Scores on each dependent measure, therefore, can be thought of as percentages of the total possible score. Because this approach makes it more difficult to interpret results in terms of the original ratingscale labels, we include these labels on all graphs of the data

Continuing involvement with the deceased and emotional resolution. To assess continuing involvement with the deceased spouse and to determine the extent of emotional resolution, respondents were asked to indicate (a) how often, during the past 3 months, they had thoughts or memories about their late husband or wife $(M=62.6, S D=36.5$, skewness $=$ -0.41 , kurtosis $=-1.33$ ), and (b) how often, during the past 3 months, they talked about their late husband or wife $(M=42.5, S D=34.7$, skewness $=0.31$, kurtosis $=-1.27$ ). For each of these questions, respondents were asked to indicate the frequency of thoughts or conversations on the following 7-point scale: 1 (never), 2 (less than once a month), 3 (about once a month), 4 (2 or 3 times a month), 5 (about once a week), 6 (2-3 times a week), and 7 (daily or almost daily).

Respondents were also asked to indicate (c) how often thinking or talking about their late husband or wife made them feel happy $(M=58.7$,

\footnotetext{
${ }^{1}$ This excludes 22 respondents who were separated before widowhood.
} 
$S D=34.1$, skewness $=-0.33$, kurtosis $=-1.01)$ and (d) how often thinking or talking about him or her made them feel sad or upset $(M=$ $43.1, S D=32.1$, skewness $=0.29$, kurtosis $=-0.79)$ on the following 5-point scale: 1 (never), 2 (rarely), 3 (sometimes), 4 (often), and 5 (almost always).

Finally, respondents were asked to indicate (e) whether they had experienced particular occasions during the past year (e.g., the date of their husband's or wife's death or his or her birthday) when the sadness and loneliness that they experienced right after the death returned to them on the following 5-point scale: 1 (no, never), 2 (yes, but rarely), 3 (yes, some), 4 (yes, frequently), and 5 (yes, all the time). In the widowed sample, the average respondent reported a level of 37.2, with a standard deviation of 34.6 , skewness of 0.37 , and kurtosis of -1.15 . Those respondents who had experienced responses of this sort, commonly called anniversary reactions in the bereavement literature, were also asked to rate on 5-point scales (f) how long such reactions typically lasted-1 (a few moments), 2 (a few hours), 3 (a day or so), 4 (a few days), and 5 (a week or longer)—and (g) how intense such feelings usually were-1 (not at all), 2 (just a little), 3 (somewhat), 4 (quite), and 5 (extremely). The average length of anniversary reactions within the widowed sample was 20.1 units, with a standard deviation of 26.2, skewness of 1.17 , and kurtosis of 0.53 . The average intensity of anniversary reactions was 52.1 units, with a standard deviation of 28.6, skewness of 0.21 , and kurtosis of -0.82 .

These variables showed substantial intercorrelation. Frequency of thoughts about the partner was correlated .69 with frequency of conversations about the partner and .56 with frequency of anniversary reactions. Frequency of anniversary reactions was also correlated .46 with frequency of conversations about the deceased spouse and .45 with frequency of sad or upsetting thoughts and conversations about the spouse. Finally, the frequency of anniversary reactions was correlated .41 with the intensity of such reactions.

Finding meaning in the loss. To assess cognitive resolution following the loss, or the extent to which respondents had been able to come up with a satisfactory account of what had happened, respondents were asked to rate (a) whether they were currently searching to make sense or find some meaning in their spouse's death on a 5-point scale ranging from 1 (no, never) to 5 (yes, all the time). This measure had a mean of 29.5 units, a standard deviation of 31.7 , skewness of 0.63 , and kurtosis of -0.77 . Respondents who reported having ever searched for meaning were asked to rate (b) whether they had made any sense or found any meaning in their husband's or wife's death on the following 5-point scale: 1 (no, not at all), 2 (yes, a little), 3 (yes, some), 4 (yes, quite a bit), and 5 (yes, a great deal). For this measure, the mean response was 24.6 units, with a standard deviation of 32.9 , skewness of 1.05 , and kurtosis of -0.22 . Respondents were also asked to indicate how true they thought it was that (c) they did not question their spouse's death because it was meant to be $(M=70.9$, $S D=38.0$, skewness $=-0.88$, kurtosis $=-0.79$ ), (d) they felt their spouse's death was senseless and unfair $(M=28.9, S D=38.7$, skewness $=0.93$, kurtosis $=-0.74$ ), (e) they did not worry about finding meaning in their spouse's death because these things just happen $(M=$ 76.2, $S D=34.3$, skewness $=-1.17$, kurtosis $=-0.02$ ), and (f) they believed their spouse was better off now than if he or she had lived longer $(M=58.3, S D=43.0$, skewness $=-0.33$, kurtosis $=-1.62)$. These variables were measured on a 4-point scale: 1 (not at all true), 2 (somewhat true), 3 (mostly true), and 4 (very true).

The correlations among these variables were more modest than those in the previous section. Here, the extent to which respondents reported that the death was meant to be was correlated .41 with the extent to which they reported that death is something that just happens. Interestingly, the extent to which respondents reported currently searching for meaning in the death showed sizable correlations with several variables in the previous section related to continued involvement and emotional resolution. It correlated .49 with the frequency of thoughts about the spouse, .40 with the frequency of conversations about the spouse, and .52 with the duration of anniversary reactions.

Personal growth. Finally, respondents were asked two questions regarding the extent to which they had experienced personal growth as a result of the loss. Respondents were asked to indicate their agreement with the statement "I have become more self-confident as a result of having to manage without my husband/wife." The average level of this measure across the widowed sample was 70.7 units, with a standard deviation of 36.2 , skewness of -0.85 , and kurtosis of -0.71 . Respondents were also asked to evaluate how much they felt like a stronger person for coping with their spouse's death. This measure had a mean of 65.5 units, standard deviation of 37.7 , skewness of -0.60 , and kurtosis of -1.11 . For both of these questions, respondents rated their agreement on a 4-point scale ranging from 1 (not at all true) to 4 (very true). Responses to these questions were correlated .46 across the sample.

\section{Results}

\section{Characteristics of the Widowed Sample}

Table 1 summarizes the characteristics of the 768 respondents who constituted the widowed sample. As this table illustrates, the typical respondent in the study was 70 years old and had lost his or her spouse after nearly 30 years of marriage. The average age of the spouse who died was 59.2 years, and respondents had been widowed an average of 15 years at the time of the interview. Twenty percent of the sample were men.

\section{Overview of Results}

Below, we first examine various indicators of continuing psychological involvement with the spouse, such as the frequency of thoughts and memories, and indicators of emotional resolution of the loss, such as the extent to which memories made the respondent feel happy versus upset. Then, we describe the relationship between time since widowhood and various indicators of cognitive resolution of the loss. Finally, we examine indicators of positive growth and change.

\section{Analysis Approach}

Given our focus on the long-term course of adjustment, we expected to observe a temporal process of equilibration in which levels of grief process variables moved toward some long-term equilibrium level. As noted earlier, the mathematical function for modeling equilibration with time is usually a negative exponential in which temporal changes are relatively rapid at first and slow with time until an asymptote is reached. Preliminary graphical analyses confirmed our expectations for many of the process variables.

These preliminary analyses were conducted as follows. Time since widowhood was grouped into 5-year intervals, and mean levels of each process variable in each interval were calculated, adjusting for a set of control variables. These included demographic variables such as sex, race, education, and age of respondent; contextual variables relating to the loss event such as age of spouse and number of children at the time of widowhood, whether the death was expected or not, and whether the death was due to murder, accident, or suicide; and, finally, a measure of current relationship status, that is, whether the respondent was remarried at the time of the interview. Each of the control variables was 
Table 1

Characteristics of the Widowed Sample

\begin{tabular}{|c|c|c|c|c|c|c|}
\hline \multirow[b]{2}{*}{ Characteristic } & \multicolumn{2}{|c|}{ Total $(n=768)$} & \multicolumn{2}{|c|}{$\operatorname{Men}(n=149)$} & \multicolumn{2}{|c|}{ Women $(n=619)$} \\
\hline & $M$ & $S D$ & $M$ & $S D$ & $M$ & $S D$ \\
\hline Average age (years) & 70.0 & 11.1 & 70.6 & 12.1 & 69.9 & 10.8 \\
\hline Average age when widowed (years) & 55.2 & 14.8 & 57.1 & 16.6 & 54.7 & 14.3 \\
\hline Education (number of years) & 9.9 & 3.7 & 9.7 & 4.1 & 10.0 & 3.7 \\
\hline Spouse's age at death (years) & 59.2 & 15.4 & 54.9 & 16.6 & 60.3 & 15.0 \\
\hline Total number of children & 3.0 & 2.4 & 3.2 & 2.5 & 3.0 & 2.4 \\
\hline$\%$ currently married & 15.9 & & 30.2 & & 12.4 & \\
\hline \multicolumn{7}{|l|}{ Race } \\
\hline White (\%) & 63.9 & & 65.1 & & 63.6 & \\
\hline Black (\%) & 34.1 & & 30.9 & & 34.9 & \\
\hline Other $(\%)$ & 2.0 & & 4.0 & & 1.5 & \\
\hline \multicolumn{7}{|l|}{ Religion } \\
\hline Protestant (\%) & 76.2 & & 69.8 & & 77.7 & \\
\hline Catholic (\%) & 18.6 & & 20.8 & & 18.1 & \\
\hline Jewish (\%) & 1.6 & & 1.3 & & 1.6 & \\
\hline Other/none (\%) & 3.6 & & 8.1 & & 2.6 & \\
\hline Time since death (years) & 14.8 & 11.7 & 13.5 & 12.6 & 15.2 & 11.5 \\
\hline Died suddenly $(\%)$ & 47.9 & & 43.0 & & 49.1 & \\
\hline Number of years married & 29.0 & 16.0 & 29.5 & 16.4 & 28.9 & 16.0 \\
\hline
\end{tabular}

included because it could plausibly be associated with both time since widowhood and the grief response, thereby leading to a bias in the relationship between the two. These adjusted means (also knows as least squares means) represent the predicted level of a given outcome for each time interval for individuals at the mean on the control variables, and they were computed using the LSMEANS option in the general linear model (GLM) procedure available in SAS software (SAS Institute, 2004).

As we illustrate in the graphs presented below, although many of the process variables showed a negative exponential pattern with time, some showed what appeared to be a linear trend, and some showed no relationship with time. In our modeling of the functional form, we allowed for all three possibilities. The simplest or null model, shown in Figure 1(i), was one in which, after adjusting for the control variables $\left(x_{i}\right)$ listed above, there was no relationship between time since widowhood $(t)$ and a given process measure, labeled $y$. In formal terms,

$$
y=a+0 \times t+\sum c_{i} x_{i}+\varepsilon .
$$

Each control variable $\left(x_{i}\right)$ was mean centered, that is, the sample mean was subtracted from each person's score (resulting in a mean of 0 for all control variables). With the controls coded in this way, the intercept $a$ is the mean of $y$, and the relationship between time ( $t$ ) and $y$ net of the controls is constrained to be 0. Each $c_{i}$ represents the unique linear relationship between control variable $i$ and $y$. Finally, $\varepsilon$ is a random variable that represents all other remaining influences on $y$. It is assumed that these (a) average to zero, (b) are uncorrelated with the other variables in the model, and (c) have the same variability over time and the covariates. Note that time $t$ in this and the other two regression models discussed below is the original, continuous time scale, not the categorized version of time since widowhood used to estimate the adjusted means discussed above.

The second or linear model, shown in Figure 1(ii), specified that after adjusting for the control variables, there was a linear relationship between time since widowhood and $y$, as follows:

$$
y=a^{\prime}+b \times t+\sum c_{i}^{\prime} x_{i}+\varepsilon^{\prime} .
$$

The intercept $a^{\prime}$ is the value of $y$ for a typical person who has just been widowed. The slope $b$ is the expected difference in each recovery measure $y$ associated with a one-year difference in time since widowhood. Here, each $c_{i}^{\prime}$ represents the unique linear relationship between control variable $i$ and $y$, adjusting for time. As in the null model, $\varepsilon^{\prime}$ is a random variable related to the unmeasured (i) Null Model

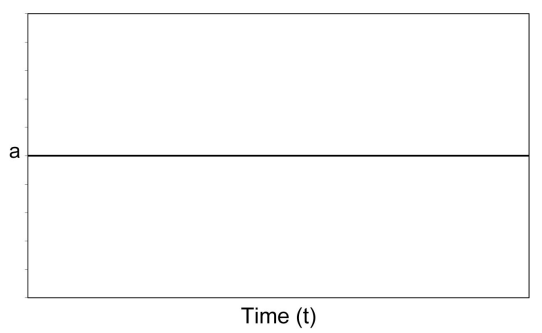

(ii) Linear Model

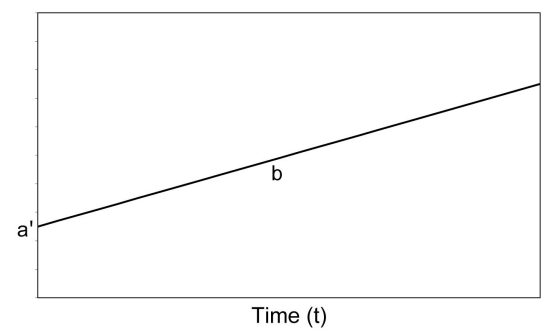

(iii) Negative Exponential Model

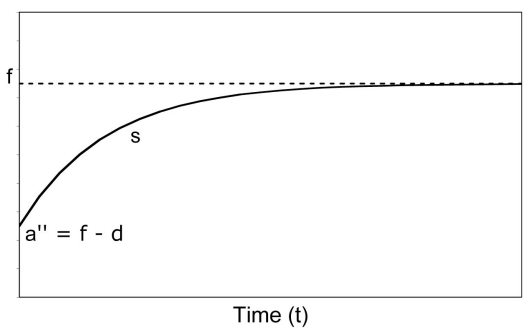

Figure 1. Characteristic forms of the null, linear, and negative exponential models. 
Table 2

Goodness-of-Fit and Improvement-in-Fit Measures for Null, Linear, and Negative Exponential Models: Measures of Continued Involvement and Emotional Resolution

\begin{tabular}{|c|c|c|c|c|}
\hline Measure & RMSE & $R_{a d j}^{2}$ & $\Delta R_{a d j}^{2}$ & $p$ \\
\hline \multicolumn{5}{|c|}{ Frequency of thoughts and memories } \\
\hline Null model & 21.4 & .3696 & & \\
\hline Linear model & 20.6 & .4151 & .0455 & $<.001$ \\
\hline Negative exponential model & 20.5 & .4173 & .0477 & $<.001$ \\
\hline \multicolumn{5}{|l|}{ Frequency of conversations } \\
\hline Null model & 22.5 & .2142 & & \\
\hline Linear model & 21.4 & .2926 & .0784 & $<.001$ \\
\hline Negative exponential model & 21.2 & .3053 & .0911 & $<.001$ \\
\hline \multicolumn{5}{|l|}{ Positive affect } \\
\hline Null model & 25.0 & .0595 & & \\
\hline Linear model & 25.0 & .0587 & -.0008 & .536 \\
\hline Negative exponential model & 25.0 & .0608 & .0013 & .227 \\
\hline \multicolumn{5}{|l|}{ Negative affect } \\
\hline Null model & 22.8 & .0710 & & \\
\hline Linear model & 22.6 & .0873 & .0163 & $<.001$ \\
\hline Negative exponential model & 22.5 & .0969 & .0259 & $<.001$ \\
\hline \multicolumn{5}{|c|}{ Frequency of anniversary reactions } \\
\hline Null model & 23.6 & .1320 & & \\
\hline Linear model & 22.1 & .2404 & .1085 & $<.001$ \\
\hline Negative exponential model & 21.9 & .2512 & .1192 & $<.001$ \\
\hline \multicolumn{5}{|l|}{ Length of anniversary reactions } \\
\hline Null model & 18.9 & .0131 & & \\
\hline Linear model & 18.9 & .0124 & -.0006 & .404 \\
\hline Negative exponential model & 19.0 & .0117 & -.0013 & .505 \\
\hline \multicolumn{5}{|l|}{ Intensity of anniversary reactions } \\
\hline Null model & 21.1 & .0332 & & \\
\hline Linear model & 20.9 & .0479 & .0147 & .004 \\
\hline Negative exponential model & 20.5 & .0875 & .0543 & $<.001$ \\
\hline
\end{tabular}

Note. $\quad$ RMSE = root-mean-square error

influences on $y$, conforming to the same set of assumptions laid out above.

The third or negative exponential model, illustrated in Figure 1(iii), specified that after adjusting for the control variables $\left(x_{i}\right)$, there was a negative exponential relationship between time since widowhood $(t)$ and $y$ such that adjustment was relatively rapid at first but gradually slowed until an asymptote was reached. The model was as follows:

$$
y=f-d \times e^{-s \times t}+\sum c_{i}^{\prime \prime} x_{i}+\varepsilon^{\prime \prime},
$$

in which $y$ is the measure of recovery, $f$ is the final or asymptotic level of $y, d$ is the distance between the initial level and the final level of $y, e$ is a mathematical constant representing the base of the natural logarithm, and $t$ is time in years since widowhood. The final parameter, $s$, is known as the decay constant. It is a positive number related to the rate of adjustment, with larger numbers representing more rapid adjustment. In this specification, $f-d$ is the equivalent of $a$ and $a^{\prime}$ in the previous models, that is, $a^{\prime \prime}$. Again, each $c_{i}^{\prime \prime}$ represents the unique linear relationship between control variable $i$ and $y$. Once again, $\varepsilon^{\prime \prime}$ corresponds to all other random, unmeasured influences on $y$. The same assumptions described for the null model also apply to this residual term in the negative exponential model.

The estimation of all three models was accomplished using the NLIN procedure available with SAS software (SAS Institute, 2004), although the null and linear models could have equivalently been estimated with several other SAS procedures (e.g., REG or
GLM) or any software capable of least squares linear regression. ${ }^{2}$ To determine which of the three models was most appropriate for each measure, we computed adjusted goodness-of-fit indices for each model for each measure (shown in Tables 2 and 3). Like many other methods for computing regression estimates, the NLIN procedure uses least squares estimation to arrive at these estimates (SAS Institute, 2004). That is, the estimates produced are those that minimize the sum of squared residuals.

Note that because the linear and negative exponential models are not nested models, they cannot be directly compared in terms of their fit. They can, however, be compared in terms of how much each improves the fit compared with the null model. A simple change in $R^{2}$ statistic would not suffice for this purpose, though, because it does not take the relative degrees of freedom of the two models into account, namely, that one degree of freedom is lost when fitting the linear model, whereas two degrees of freedom are lost when fitting the negative exponential model. To account for the different degrees of freedom of the linear and negative expo-

\footnotetext{
${ }^{2}$ Unlike some other regression programs, the NLIN procedure requires the user to provide starting values for the parameter estimates. These starting values can be estimated from descriptive data and plots. An additional feature of NLIN is the ability to set bounds on the parameter estimates. In all negative exponential regression analyses presented here, $f$ and $f-d$ from Equation 3 were constrained to be between 0 and 100, and $s$ was constrained to be 0 or larger.
} 
Table 3

Goodness-of-Fit and Improvement-in-Fit Measures for Null, Linear, and Negative Exponential Models: Measures of Finding Meaning and Personal Growth

\begin{tabular}{|c|c|c|c|c|}
\hline Measure & RMSE & $R_{a d j}^{2}$ & $\Delta R_{a d j}^{2}$ & $p$ \\
\hline \multicolumn{5}{|c|}{ Finding meaning } \\
\hline \multicolumn{5}{|l|}{ Death was meant to be } \\
\hline Null model & 28.5 & .0825 & & \\
\hline Linear model & 28.2 & .0983 & .0158 & $<.001$ \\
\hline Negative exponential model & 28.2 & .0977 & .0151 & $<.001$ \\
\hline \multicolumn{5}{|l|}{ Death just happens } \\
\hline Null model & 24.6 & .0613 & & \\
\hline Linear model & 24.3 & .0879 & .0266 & $<.001$ \\
\hline Negative exponential model & 24.3 & .0864 & .0250 & $<.001$ \\
\hline \multicolumn{5}{|l|}{$\begin{array}{l}\text { Currently searching for } \\
\text { meaning }\end{array}$} \\
\hline Null model & 22.9 & .1631 & & \\
\hline Linear model & 22.0 & .2246 & .0615 & $<.001$ \\
\hline Negative exponential model & 21.8 & .2385 & .0754 & $<.001$ \\
\hline \multicolumn{5}{|l|}{ Ever find meaning } \\
\hline Null model & 23.5 & -.0059 & & \\
\hline Linear model & 23.6 & -.0087 & -.0028 & .678 \\
\hline Negative exponential model & 23.6 & -.0145 & -.0086 & .814 \\
\hline \multicolumn{5}{|l|}{ Death was senseless } \\
\hline Null model & 27.4 & .1566 & & \\
\hline Linear model & 27.3 & .1673 & .0107 & .001 \\
\hline Negative exponential model & 27.3 & .1677 & .0111 & .003 \\
\hline \multicolumn{5}{|l|}{ Spouse is better off now } \\
\hline Null model & 30.8 & .1173 & & \\
\hline Linear model & 30.8 & .1170 & -.0003 & .381 \\
\hline Negative exponential model & 30.8 & .1159 & -.0014 & .379 \\
\hline \multicolumn{5}{|c|}{ Personal growth } \\
\hline \multicolumn{5}{|l|}{ Gained self-confidence } \\
\hline Null model & 25.3 & .1045 & & \\
\hline Linear model & 25.2 & .1102 & .0058 & .015 \\
\hline Negative exponential model & 25.2 & .1112 & .0067 & .022 \\
\hline \multicolumn{5}{|l|}{ Stronger person as a result } \\
\hline Null model & 26.3 & .1014 & & \\
\hline Linear model & 26.3 & .1002 & -.0011 & .841 \\
\hline Negative exponential model & 26.3 & .1029 & .0015 & .195 \\
\hline
\end{tabular}

Note. $\quad$ RMSE $=$ root-mean-square error

nential models, we computed adjusted $R^{2}$ and change in adjusted $R^{2}$ values to assess model fit (see Tables 2 and 3 ). ${ }^{3}$

For each measure, these tables show the $R_{a d j}^{2}$ value for each model, the improvement in fit for both the linear and negative exponential models compared with the null model, and the significance test of the improvements in fit. In most cases, both the linear and negative exponential models improved the fit compared with the null model. In these cases, we directly compared the change in $R_{a d j}^{2}$ values of the two models. We used the convention that a difference in change in $R_{a d j}^{2}$ of .0100 (i.e., $1 \%$ ) between the two models indicated a sizable difference in fit. Generally, the negative exponential model showed a greater improvement in fit than the linear model, confirming the descriptive evidence discussed above. In such cases, we show (in Figures 2, 3, and 4) the fitted function for the negative exponential model. In cases in which the linear model showed a greater improvement in fit, we show the linear function. For simplicity, in cases in which both the linear and negative exponential models improved the fit to an approximately equal degree, we show only the fitted results for the negative exponential model in the figures. In cases in which neither improved the fit, we show the implied zero-slope line from the null model.

On the basis of the fit statistics presented in Tables 2 and 3, Tables 4, 5, and 6 present the regression estimates and several additional pieces of information regarding the best fitting model or models for each dependent variable. First, these tables identify which of the three models best described each outcome. In cases in which the linear and negative exponential models showed equal

\footnotetext{
${ }^{3}$ Both normal $R^{2}$ values and $R_{\text {adj }}^{2}$ values are easily computed from the analysis of variance table that accompanies regression analyses in most common statistical packages. Whereas $R^{2}$ is simply the sum of squares accounted for by the model divided by the total sum of squares, $R_{a d j}^{2}$ is given by the following formula:

$$
R_{\text {adj }}^{2}=\frac{S S_{\text {model }} / d f_{\text {model }}}{S S_{\text {total }} / d f_{\text {total }}} .
$$
}


(i) Frequency of Memories

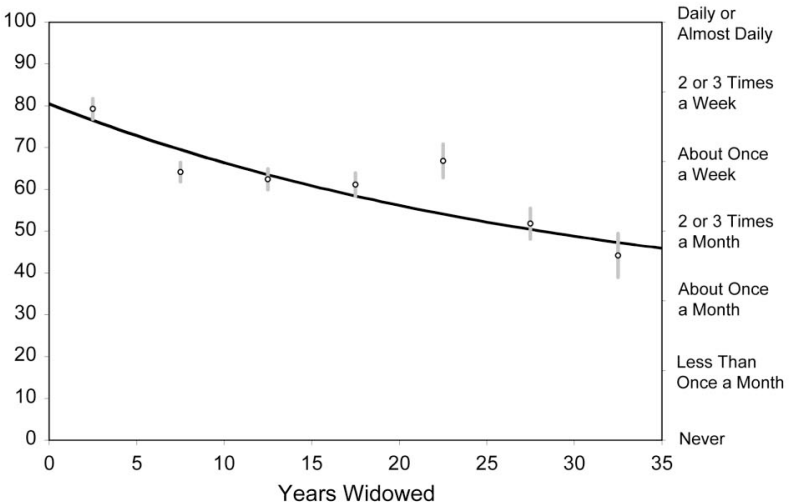

(iii) Positive and Negative Affect

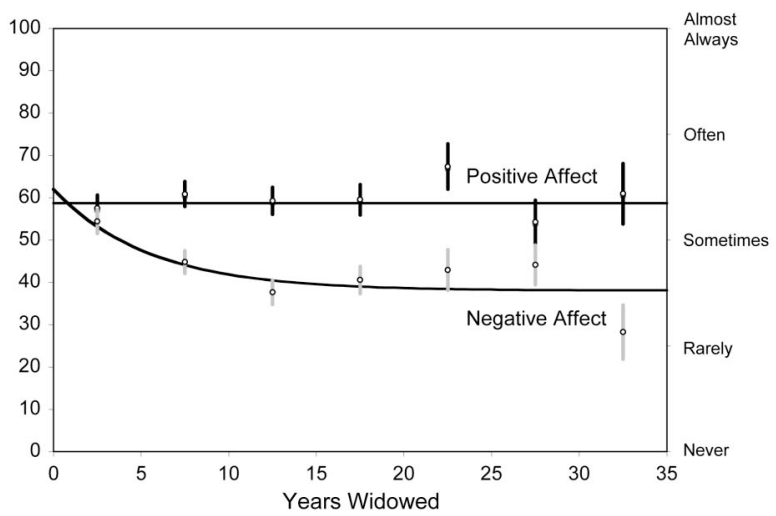

(v) Length of Anniversary Reactions

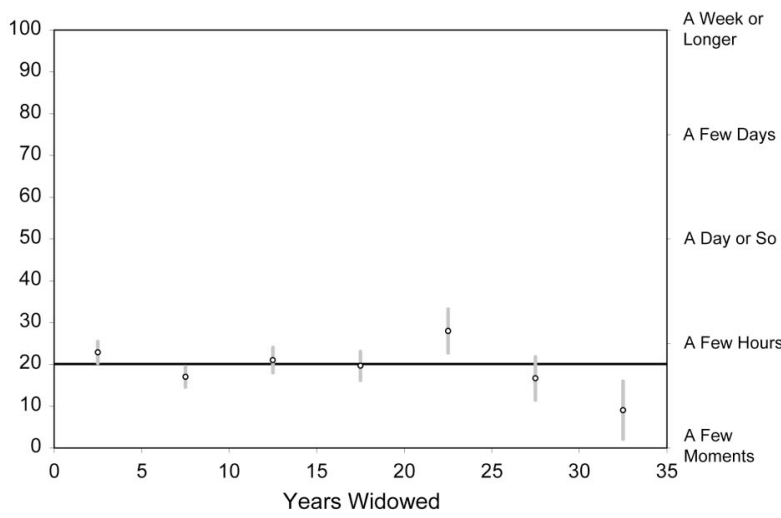

(ii) Frequency of Conversations

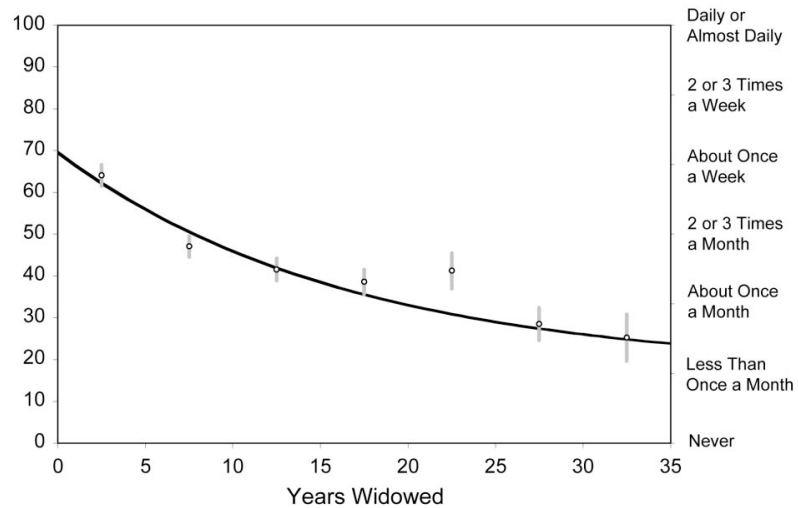

(iv) Frequency of Anniversary Reactions

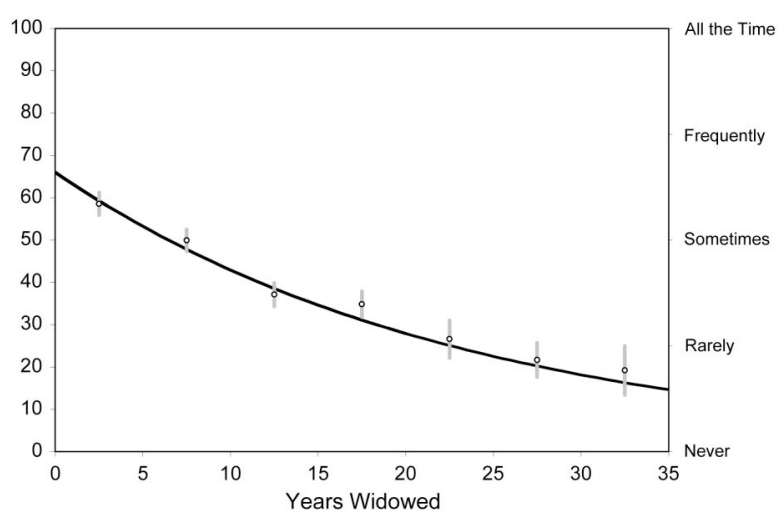

(vi) Intensity of Anniversary Reactions

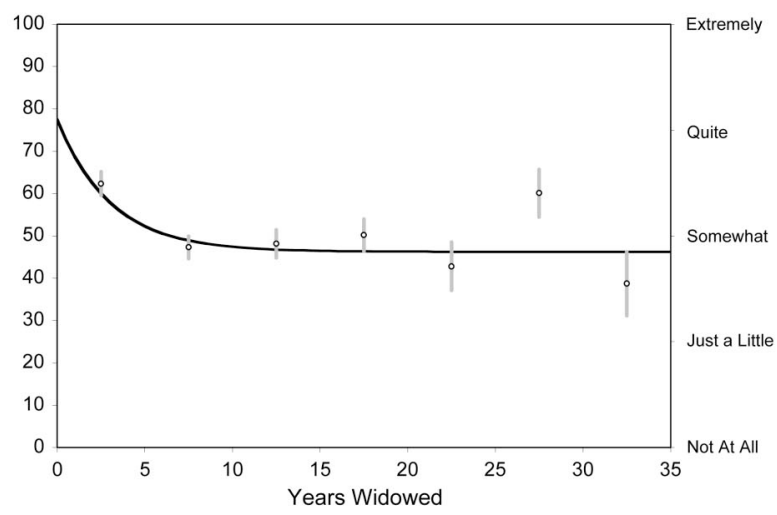

Figure 2. Functional relationships between years since widowhood and measures of continuing involvement and emotional resolution, adjusted for sex, race, education, age of respondent; age of spouse and number of children at time of widowhood; whether the death was expected or not; whether the death was due to murder, accident, or suicide; and whether the respondent became remarried. Points indicate least squares means for 5 -year intervals, and error bars represent standard errors of those means.

improvement in fit, we show results for both in the tables. We also indicate the rate of change of each measure as a function of time. For those variables showing a linear relationship, this corresponds to $b$ in Equation 2 and represents the number of units on the dependent variable corresponding to a one-year difference in time since widowhood, adjusting for the control variables listed above. For example, knowing that the linear rate of change in frequency of thoughts about the deceased spouse is -.89 units per year means that we would expect respondents widowed 10 years apart to differ on this variable by 8.9 units. For those variables showing a negative exponential relationship, the value listed in the table corresponds to $s$ in Equation 3, although no such easy calculation of adjustment level is possible here because the rate of change depends on time itself. To determine how respondents were doing 
(i) Death was Meant to $\mathrm{Be}$

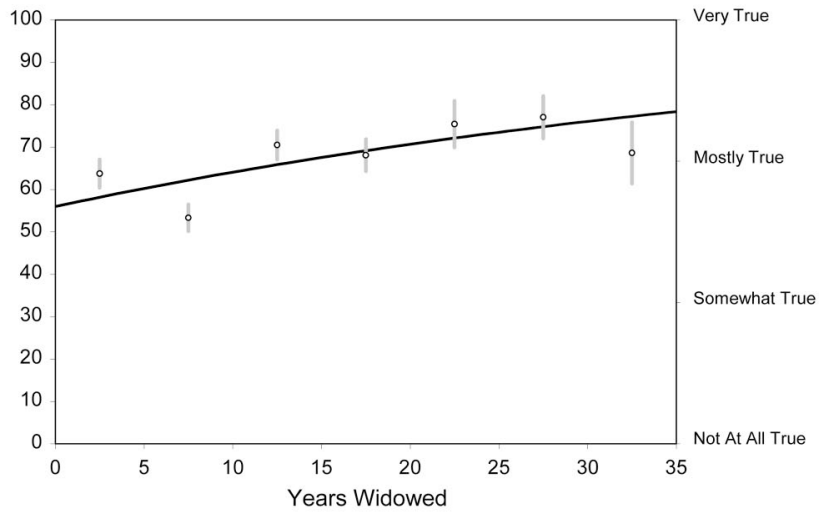

(iii) Currently Searching for Meaning

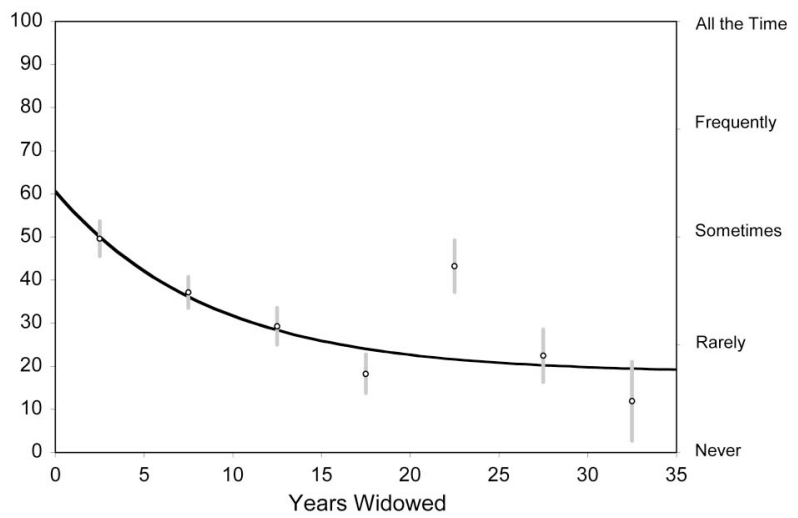

(v) Death was Senseless

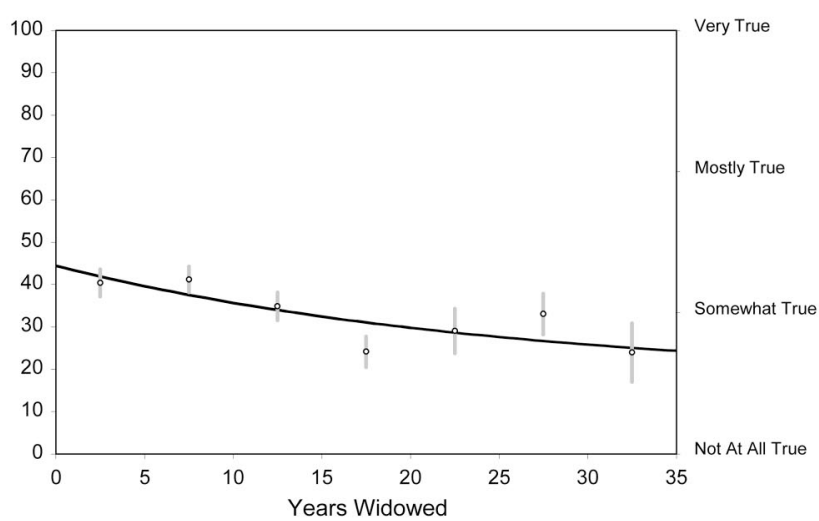

(ii) Death Just Happens

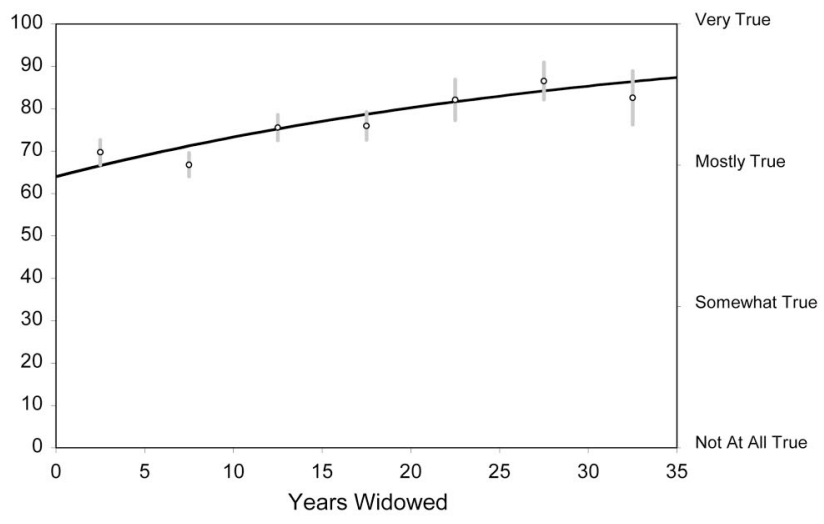

(iv) Ever Find Meaning

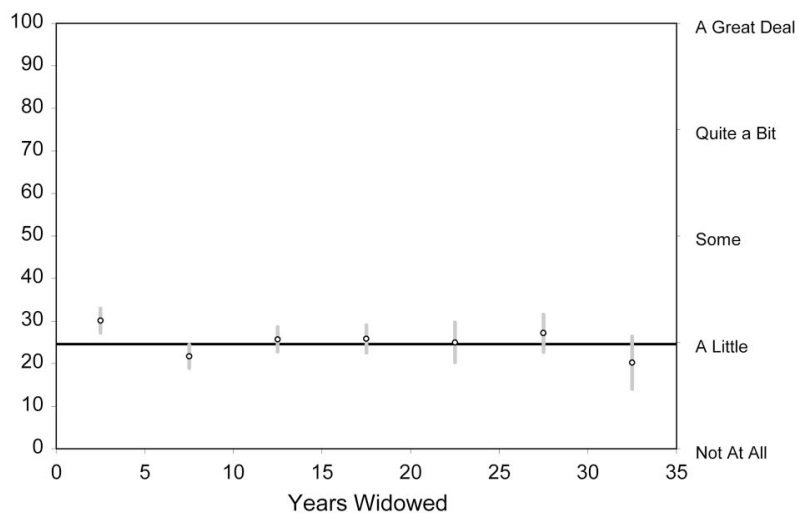

(vi) Spouse is Better-Off Now

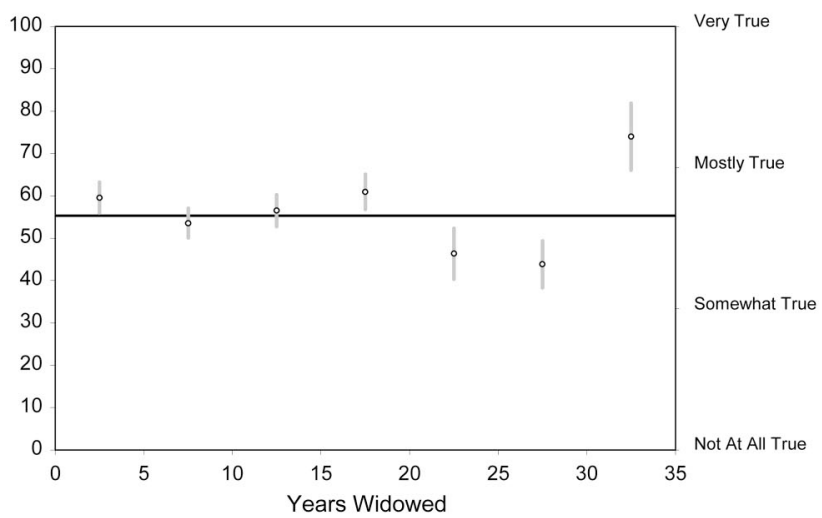

Figure 3. Functional relationships between years since widowhood and measures of meaning finding, adjusted for sex, race, education, age of respondent; age of spouse and number of children at time of widowhood; whether the death was expected or not; whether the death was due to murder, accident, or suicide; and whether the respondent became remarried. Points indicate least squares means for 5-year intervals, and error bars represent standard errors of those means.

after a specified number of years, it is necessary to calculate the predicted levels of $y$ using Equation 3.

Tables 4-6 provide several additional pieces of information about the models we estimated. First, they provide the initial value or intercept predicted for each model. For all three models, this has the same interpretation, namely, the predicted level of the depen- dent variable for people at the point of widowhood, adjusting for the control variables. Second, for measures in which the negative exponential model provided the best fit, these tables provide what we call the $90 \%$ asymptotic level. This value represents the level of adjustment corresponding to $90 \%$ of the distance between the initial value and the asymptotic value. Finally, for those variables 
(i) Gained Self-Confidence

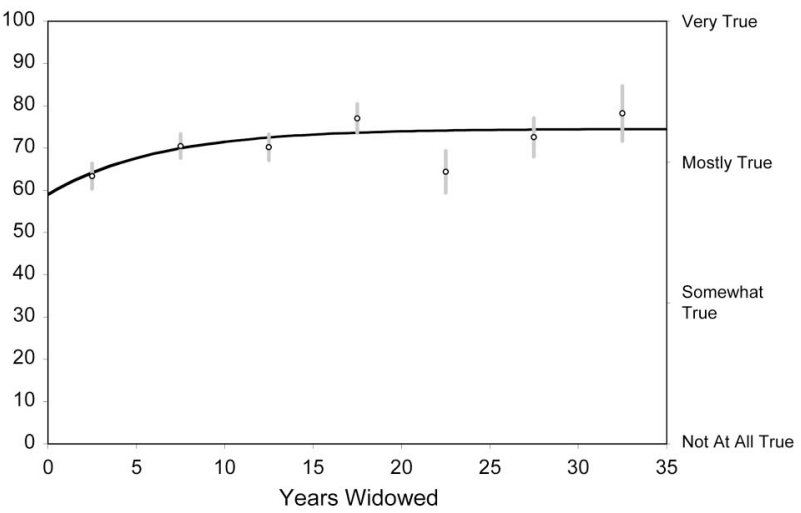

(ii) Stronger Person as a Result

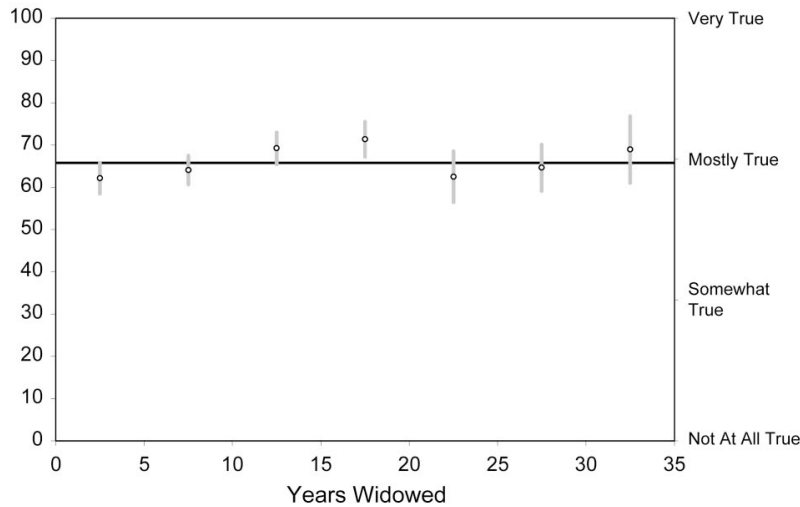

Figure 4. Functional relationship between years since widowhood and measures of personal growth, adjusted for sex, race, education, age of respondent; age of spouse and number of children at time of widowhood; whether the death was expected or not; whether the death was due to murder, accident, or suicide; and whether the respondent became remarried. Points indicate least squares means for 5-year intervals, and error bars represent standard errors of those means.

in which there was a negative exponential relationship between time since widowhood and adjustment, we used Equation 3 to estimate the number of years it would take to reach $25 \%, 50 \%$, $75 \%$, and $90 \%$ of the distance to the asymptotes. These values provide a view of adjustment as a function of time for the negative exponential models that is easier to interpret than the $s$ parameter of Equation 3. In those cases in which the relationship between the dependent variable and time since widowhood is linear, identifying a specific long-term recovery level is not possible because the rate of recovery does not change over time. Thus, for those variables in which the model was linear, we left the $25 \%, 50 \%, 75 \%$, and $90 \%$ columns blank.

\section{A Note on the Figures}

Figures 2-4 show the best fitting model for each measure of recovery as well as the least squares means estimated for each 5-year interval since widowhood (described earlier). Although the total sample contained respondents widowed as little as a few months to as long as 64 years prior to the survey, small cell sizes

Table 4

Linear and Negative Exponential Regressions Relating Indicators of Continuing Involvement and Emotional Resolution to the Duration of Time Since Widowhood

\begin{tabular}{|c|c|c|c|c|c|c|c|c|c|c|}
\hline \multirow{2}{*}{$\begin{array}{l}\text { Dependent variable \& form } \\
\text { of relationship }\end{array}$} & \multicolumn{6}{|c|}{ Level of dependent variable } & \multicolumn{4}{|c|}{$\begin{array}{c}\text { Number of years to } \% \text { of } \\
\text { asymptotic level }\end{array}$} \\
\hline & Speed of change & $S E$ & Initial & $S E$ & $90 \%$ asymptotic & $S E$ & $25 \%$ & $50 \%$ & $75 \%$ & $90 \%$ \\
\hline \multicolumn{11}{|l|}{ Frequency of memories } \\
\hline Linear & $-.89 *$ & .11 & $76.3^{*}$ & 2.0 & & & & & & \\
\hline Negative exponential & $.03 \dagger$ & .02 & $80.5^{*}$ & 3.0 & $34.5^{*}$ & 8.6 & 8.9 & 21.4 & 42.9 & $71.3^{\mathrm{a}}$ \\
\hline \multicolumn{11}{|l|}{ Frequency of conversations } \\
\hline Negative exponential & $.06^{*}$ & .02 & $69.5^{*}$ & 3.4 & $22.8^{*}$ & 3.1 & 4.7 & 11.4 & 22.8 & 37.9 \\
\hline $\begin{array}{l}\text { Positive affect } \\
\text { Null }\end{array}$ & 0 & \multicolumn{9}{|c|}{ Positive affect ${ }^{\mathrm{b}}$} \\
\hline \multicolumn{11}{|l|}{ Negative affect $^{\mathrm{b}}$} \\
\hline $\begin{array}{l}\text { Negative exponential } \\
\text { Frequency of anniversary reactions }\end{array}$ & $.18 *$ & .08 & $61.4^{*}$ & 5.1 & $39.8^{*}$ & 1.6 & 1.6 & 3.8 & 7.6 & 12.6 \\
\hline $\begin{array}{l}\text { Negative exponential } \\
\text { Duration of anniversary reactions }\end{array}$ & $.04 *$ & .00 & $66.0 *$ & 3.1 & $6.6^{*}$ & 1.4 & 6.7 & 16.1 & 32.2 & 53.5 \\
\hline $\begin{array}{l}\text { Null } \\
\text { Intensity of anniversary reactions }\end{array}$ & 0 & & $19.1^{*}$ & 1.2 & & & & & & \\
\hline Negative exponential & $.32 *$ & .11 & $78.5^{*}$ & 5.8 & $50.4 *$ & 1.9 & 0.9 & 2.1 & 4.2 & 7.0 \\
\hline
\end{tabular}

Note. For linear results, rates are in units per year. All analyses adjust for sex, race, education, age of respondent, age of spouse, and number of children at time of widowhood; whether the death was expected or not; whether the death was due to murder, accident, or suicide; and whether the respondent became remarried.

${ }^{\text {a }}$ Projected value is beyond the range of the data. $\quad{ }^{\mathrm{b}}$ Total $n=697 . \quad{ }^{\mathrm{c}}$ Total $n=484$.

$\dagger p<.10$. * $p<.05$. 
Table 5

Linear and Negative Exponential Regressions Relating Indicators of Meaning Finding to the Duration of Time Since Widowhood

\begin{tabular}{|c|c|c|c|c|c|c|c|c|c|c|}
\hline \multirow[b]{2}{*}{ Dependent variable \& form of relationship } & \multicolumn{6}{|c|}{ Level of dependent variable } & \multicolumn{4}{|c|}{$\begin{array}{c}\text { Number of years to } \% \text { of } \\
\text { asymptotic level }\end{array}$} \\
\hline & Speed of change & $S E$ & Initial & $S E$ & $90 \%$ asymptotic & $S E$ & $25 \%$ & $50 \%$ & $75 \%$ & $90 \%$ \\
\hline \multicolumn{11}{|l|}{ View death as meant to be } \\
\hline Linear & $.60 *$ & .16 & $57.7 *$ & 2.7 & & & & & & \\
\hline Negative exponential & $.02 *$ & .01 & $56.0 *$ & 3.4 & $95.6^{*}$ & 2.7 & 14.2 & 34.1 & $68.3^{\mathrm{b}}$ & $113.4^{\mathrm{b}}$ \\
\hline \multicolumn{11}{|l|}{ View death as something that just happens } \\
\hline Linear & $.65^{*}$ & .14 & $66.0 *$ & 2.3 & & & & & & \\
\hline Negative Exponential & $.03 *$ & .01 & $64.0 *$ & 3.2 & $96.4^{*}$ & 1.8 & 9.6 & 23.1 & 46.1 & $76.8^{\mathrm{b}}$ \\
\hline \multicolumn{11}{|l|}{ Currently searching for meaning? ${ }^{\mathrm{a}}$} \\
\hline Negative exponential & $.12 *$ & .05 & $60.1 *$ & 6.5 & $22.2 *$ & 2.4 & 2.5 & 6.0 & 12.0 & 19.9 \\
\hline \multicolumn{11}{|l|}{ If searched, found meaning? ${ }^{\mathrm{a}}$} \\
\hline Null & 0 & & $25.9^{*}$ & 1.7 & & & & & & \\
\hline \multicolumn{11}{|l|}{ View death as senseless and unfair } \\
\hline Linear & $-.50 *$ & .15 & $41.4 *$ & 2.6 & & & & & & \\
\hline Negative exponential & .03 & .04 & $44.4 *$ & 4.1 & $20.3^{*}$ & 8.0 & 7.3 & 17.6 & 35.2 & 58.5 \\
\hline \multicolumn{11}{|l|}{ View of spouse as better off now } \\
\hline Null & 0 & & $55.3^{*}$ & 1.5 & & & & & & \\
\hline
\end{tabular}

Note. For linear results, rates are in units per year. All analyses adjust for sex, race, education, age of respondent, age of spouse, and number of children at time of widowhood; whether the death was expected or not; whether the death was due to murder, accident, or suicide; and whether the respondent became remarried.

a Total $n=313$. ${ }^{\mathrm{b}}$ Projected value is beyond the range of the data.

$* p<.05$.

limited the interpretability of the least squares means analysis to widows of 35 years or less. For this reason, Figures 2-4 depict only the first 35 years since widowhood, although all analyses made use of the entire widowed sample. Also, each of these figures has two ordinate axes, one showing the $0-100$ scale of the dependent measure and one showing the actual verbal labels the respondents were given.

\section{Continuing Involvement and Emotional Resolution}

We first present results for measures of continuing involvement with the lost loved one, such as the frequency of memories and conversations about one's spouse, and measures of emotional resolution, such as positive and negative feelings from thinking and talking about the loss and the frequency, duration, and intensity of feeling upset with reminders of the loss. Table 2 summa- rizes the goodness-of-fit results, whereas Table 4 summarizes the fitted models.

For frequency of thoughts and memories about the deceased spouse, both the linear and negative exponential models showed equal improvement in fit over the null model. For simplicity, we chose to graph only the negative exponential results $\left(\Delta R_{a d j}^{2}=\right.$ $.0477, p<.001$ ), as shown in Figure 2(i). These results show a moderate decline in thoughts and memories as a function of time since widowhood. Respondents who were recently widowed reported having thoughts and memories of their loved one approximately two to three times per week (corresponding to 80.5 units). The $90 \%$ asymptotic value (34.5 units) corresponds to thoughts or memories about once per month, and the number of years widowed corresponding to this value is 71.3 years. This value is beyond the observed range of our data ( $0-64$ years postwidowhood).

Table 6

Linear and Negative Exponential Regressions Relating Perceptions of Personal Growth to the Duration of Time Since Widowhood

\begin{tabular}{|c|c|c|c|c|c|c|c|c|c|c|}
\hline \multirow[b]{2}{*}{$\begin{array}{l}\text { Dependent variable \& } \\
\text { form of relationship }\end{array}$} & \multicolumn{6}{|c|}{ Level of dependent variable } & \multicolumn{4}{|c|}{$\begin{array}{c}\text { Number of years to } \% \text { of } \\
\text { asymptotic level }\end{array}$} \\
\hline & $\begin{array}{l}\text { Speed of } \\
\text { change }\end{array}$ & $S E$ & Initial & $S E$ & $\begin{array}{c}90 \% \\
\text { asymptotic }\end{array}$ & $S E$ & $25 \%$ & $50 \%$ & $75 \%$ & $90 \%$ \\
\hline \multicolumn{11}{|l|}{ Increased self-confidence } \\
\hline Linear & $.34 *$ & .14 & $65.6^{*}$ & 2.4 & & & & & & \\
\hline Negative exponential & .16 & .12 & $59.0 *$ & 5.4 & $73.0 *$ & 1.5 & 1.8 & 4.3 & 8.6 & 14.2 \\
\hline \multicolumn{11}{|l|}{ Stronger person as a result } \\
\hline Null & 0 & & $65.8^{*}$ & 1.3 & & & & & & \\
\hline
\end{tabular}

Note. Rates are in units per year. All analyses adjust for sex, race, education, age of respondent, age of spouse, and number of children at time of widowhood; whether the death was expected or not; whether the death was due to murder, accident, or suicide; and whether the respondent became remarried.

$* p<.05$ 
The negative exponential model provided the best fit in the case of the frequency of conversations about the deceased spouse $\left(\Delta R_{a d j}^{2}\right.$ $=.0911, p<.001)$. The relevant fitted line is displayed in Figure 2(ii). Recently widowed respondents reported having conversations about their loved one approximately once a week (69.5 units), and respondents at the $90 \%$ asymptotic value reported conversations occurring less than once a month (22.8 units). This latter value occurs for respondents at 37.9 years postwidowhood.

Turning now to indicators of emotional resolution, for positive affect, neither the linear nor the negative exponential model improved the fit over the null model. Respondents reported experiencing happy feelings when they thought or talked about their spouse between sometimes and often (60.2 units), and this level did not vary as a function of years since widowhood. Recently widowed respondents experienced negative feelings about as often as positive ones when thinking or talking about their spouse (61.4 units), but negative feelings showed a negative exponential decrease over time $\left(\Delta R_{a d j}^{2}=.0259, p<.001\right)$. Respondents widowed for 12.6 years reported experiencing negative affect between sometimes and rarely (39.8 units), which corresponds to $90 \%$ of the distance to the asymptote. Figure 2(iii) shows the results for both positive and negative affect. Taken together, it seems that widowed persons' thoughts and conversations about their spouses become more pleasant overall as the death becomes more distant.

Table 4 also summarizes the findings regarding three questions designed to probe the frequency, duration, and intensity of what are typically called anniversary reactions in the bereavement literature. Initially, respondents experienced such reactions between sometimes and frequently (66.0 units); however, these reactions showed a negative exponential decline as a function of years since widowhood $\left(\Delta R_{a d j}^{2}=.1192, p<.001\right)$. This relationship is plotted in Figure 2(iv). Respondents widowed for 53.5 years corresponded to the $90 \%$ asymptotic value of 6.6 (almost never), suggesting that anniversary reactions may essentially disappear after several decades of widowhood. The duration of these reactions seems not to vary systematically as a function of the number of years since widowhood, as neither the linear nor the negative exponential model showed improved fit over the null model. Respondents reported that these reactions lasted a few hours or less (19.1 units), as shown in Figure 2(v). However, the intensity of these reactions did seem to vary as a function of time since widowhood. Recently widowed respondents reported quite intense anniversary reactions (78.5 units), but the intensity showed a negative exponential decline over time $\left(\Delta R_{a d j}^{2}=.0543, p<.001\right)$. Respondents widowed for 7.0 years represent the $90 \%$ asymptotic value of 50.4 units, or somewhat intense. This relationship is shown in Figure 2(vi).

\section{Finding Meaning in the Loss}

To determine whether there was a relationship between time since the loss and cognitive resolution of the loss, respondents were asked to indicate whether they agreed with the statement "I don't question my spouse's death because it was meant to be" and the statement "I don't worry about finding meaning in my spouse's death because these things just happen." As Table 5 illustrates, respondents who had lost a spouse recently showed considerable agreement with both of these statements, rating them as mostly true. In both cases, as indicated by Table 3(i), the increase in agreement with these statements over time was described equally well by the linear and negative exponential models. To simplify, only the negative exponential models are shown in Figures 3(i) and 3(ii) $\left(\Delta R_{a d j}^{2}=.0151, p<.001\right.$, and $\Delta R_{a d j}^{2}=.0250, p<.001$, respectively). These figures show that agreement with these statements increases quite steadily as a function of time since widowhood, with the $90 \%$ asymptotic levels corresponding to mostly true and occurring many decades later, as indicated in Table 5. Consistent with these findings, when asked whether they had ever found themselves searching to make sense or find meaning in the loss, $59 \%$ of the widowed respondents said that they had never done this since the loss.

The $41 \%$ of respondents who did report having searched for meaning in the death were further asked to indicate whether they had done so in the past 3 months. According to the negative exponential model, those respondents who had endured the loss most recently reported actively searching for meaning between sometimes and frequently (60.1 units). This variable showed a significant decline with time $\left(\Delta R_{a d j}^{2}=.0754, p<.001\right)$, such that those who had experienced the loss many years ago reported that they had rarely searched for meaning in the past 3 months, with a $90 \%$ asymptotic level of 22.2. This value corresponds to respondents who had been widowed for 19.9 years. Figure 3(iii) shows this relationship. When asked if they had ever found meaning in their spouse's death, respondents who had searched for meaning indicated that they had made a little sense of it (25.9 units). The extent to which respondents reported finding meaning in the death did not vary as a function of time since widowhood, as neither the linear nor the negative exponential model showed improved fit over the null model. This relationship is represented in Figure 3(iv).

Respondents were also asked to express their agreement or disagreement with the statements that they felt their spouse's death was senseless and unfair and that their spouse was better off than if he or she had lived longer. For the question of whether the death was senseless, the linear and negative exponential models showed equivalent improvement in fit over the null model, as seen in Table 3. For simplicity, only the negative exponential relationship is shown in Figure 3(v). Recently widowed respondents indicated that this statement was between somewhat and mostly true (44.4 units), and agreement with this statement decreased as a function of time since widowhood. Respondents who had been widowed for 58.5 years represented the $90 \%$ asymptotic value of 20.3 units (between not at all and somewhat true).

The extent to which respondents agreed that their spouse was better off now did not seem to vary as a function of time since widowhood. Neither the linear nor the negative exponential model showed improved fit over the null model, as shown in Table 3. On average, respondents rated this statement between somewhat and mostly true ( 55.3 units). The zero-slope line implied by the null model is shown in Figure 3(vi).

\section{Personal Growth}

Responses to the questions designed to assess perception of positive growth following the loss are presented in Table 6. For the question of whether the respondent felt an increase in selfconfidence as a result of managing the loss, both the linear and negative exponential models showed predictive improvement over the null model $\left(\Delta R_{a d j}^{2}=.0058, p=.015\right.$, and $\Delta R_{a d j}^{2}=.0067, p=$ 
.022 , respectively). Recently widowed individuals said it was mostly true (59.0 units) that they had gained self-confidence through managing alone; agreement with this statement increased as a function of time since widowhood, with those widowed 14.2 years representing the $90 \%$ asymptotic value of 73.0 units (between mostly true and very true).

Finally, widowed respondents were asked to rate their agreement with the statement that they were stronger as a result of losing their spouses. As seen in Table 3, neither the linear nor the negative exponential model showed improved fit over the null model. Respondents found this statement to be mostly true, and agreement did not differ as a function of time since widowhood. The zero-slope line implied by the null model is shown in Figure 4(ii).

\section{Discussion}

In this article, we have aimed to chart the time course of grief by focusing on continued involvement with the deceased spouse, emotional resolution, meaning finding, and feelings of personal growth. We have shown evidence that the widowed continue to talk, think, and feel emotions about their lost spouse many years (sometimes decades) later.

\section{Continuing Involvement and Emotional Resolution}

Studies have rarely focused on the length of time that people continue to experience memories and have conversations about their deceased spouse beyond the first 4 years after the loss. Such behaviors are generally regarded as signs of involvement with or attachment to the lost loved one. Our data suggest that such behavior is normal. Although memories and conversations decrease with time, they take many decades to reach their lowest level. As long as 20 years after the loss, the typical respondent still thought about his or her spouse once every week or two and had a conversation about him or her, on average, once a month. Past research has shown a decrease in thoughts about the lost spouse from 18 months to 48 months (Boerner, Wortman, \& Bonanno, 2005), and our findings extend this. An important direction for future research is to examine the reactions of others in the bereaved person's social network to discussions of a lost spouse so long after the loss. Research has shown that others sometimes try to stop the bereaved from discussing feelings associated with the loss and find these types of discussions uncomfortable (Ingram, Jones, \& Smith, 2001; Lehman, Ellard, \& Wortman, 1986).

Further information is needed regarding the functions, costs, and benefits of different types of continuing involvement for long-term well-being. The extent to which memories and conversations are beneficial may depend on whether the bereaved focuses on negative or positive aspects. Research has examined this relatively shortly after the loss and has shown that rumination, or focusing on the distressing aspects of memories, is associated with higher levels of depression 6 months after the bereavement (NolenHoeksema, Parker, \& Larson, 1994). Our recently bereaved respondents reported feeling negatively after thinking or talking about their spouse between sometimes and often. This decreased with time, such that those bereaved about 12.5 years reported negative affect between sometimes and rarely. Of course, feeling sad or upset after thinking or talking about one's spouse may not be evidence of rumination. Memories may spontaneously be upsetting and sad. Negative thoughts may not be easily controlled and sometimes can be intrusive. Future research should examine the long-term consequences of rumination, negative intrusive thoughts, and upsetting memories for well-being.

In contrast, focusing on the positive aspects of memories of the deceased can be associated with good adjustment (W. Stroebe \& Schut, 2001). Our recently bereaved participants and those bereaved for decades reported that positive affect sometimes resulted from memories and conversations; the frequency did not change with time since loss. It is interesting that although the frequency of thoughts that result in feeling upset decreases with time, the frequency of thoughts that result in feeling happy does not. These positive thoughts may serve to maintain a bond with the deceased, as suggested by Weiss (2001). Future research should focus on the benefits of positive memories and the extent to which they are linked to negative thoughts and feelings. For example, does one get to a point in time at which fond memories no longer trigger both happiness and sadness, leading to a bittersweet feeling, but rather trigger only other positive thoughts and feelings? Are there individual differences in the extent to which positive memories prime negative thoughts and feelings? Further directions for future research could examine how conversations, memories, and adjustment are related in the long term, decades after the loss.

On average, our bereaved participants sometimes or rarely experienced anniversary reactions (i.e., experienced painful thoughts about the loss or became upset in the face of reminders) after several decades. The frequency of anniversary reactions sharply decreased over time from frequently to rarely over about 2.5 decades. It takes about 53 years for the frequency of anniversary reactions to nearly disappear. The intensity of these reactions drops quickly in the first few years and then slows. However, the duration of these reactions, a few hours, does not change with time since bereavement. It is common for anniversary reactions to be experienced at least sometimes and at somewhat intense levels for a few hours or less for 7-8 years postloss. Rando (1993) has maintained that mourners who show these reactions are often inappropriately labeled as showing pathological mourning. According to Archer (1999), anniversary reactions are commonly regarded by the bereaved as a setback in their recovery and may fuel their fears that they will never be able to master the loss. It is important for clinicians to prepare clients for the possibility that such reactions may emerge and to normalize such feelings once they have occurred. Anniversaries may provide an opportunity for the bereaved to have a time-limited experience of memories and conversations about the lost spouse; this may be particularly true for cultural practices that have ritualized anniversaries, such as yahrzeit in the Jewish tradition. ${ }^{4}$ Our results suggest that anniversary reactions can occur decades after the loss (albeit infrequently) and should not be pathologized.

The long-term responses to the loss that were documented are all the more striking when one considers that the respondents in our study most affected by the loss of a spouse - those who had died, were too ill to be interviewed, or were institutionalized-are by definition excluded from a national probability sample of this sort. In addition, $15.9 \%$ of our ever-widowed sample were remar-

\footnotetext{
${ }^{4}$ We thank an anonymous reviewer for suggesting this interpretation.
} 
ried at the time of interview, and we might have expected these individuals to show better adjustment. Moreover, these responses are averaged over bereaved spouses who suffered many different kinds of loss. On the basis of what is known about risk factors for recovery, we would expect that the consequences of the loss would last even longer when the death was sudden and unexpected, was untimely, or occurred because of someone else's negligence (see W. Stroebe \& Stroebe, 1987, or Wortman \& Silver, 1990). We statistically controlled for many of these risk factors in the present analyses. It is a task for future research to examine the different long-term trajectories for people who differ on levels of these and other risk factors. Bonanno et al. (2002) have successfully examined some of these issues in an article that focused on the relatively short-term (6 and 18 months postloss) trajectory of grief reactions; this should be extended by looking at risk factors and long-term adjustment.

\section{Finding Meaning in the Loss}

Over time, many individuals who lose a spouse may be able to achieve a state of cognitive resolution concerning the loss. Those individuals who had experienced the loss most recently expressed considerable agreement with statements indicating that they did not question the loss because it was meant to be and because such things just happen; this agreement increased with time. Also, the majority (59\%) indicated that they accepted the loss and had never searched for meaning regarding why the death had occurred; this is consistent with past research that focused on the 18 months after the loss (e.g., Bonanno et al., 2004). Among those who searched for meaning, the recently bereaved did so between sometimes and frequently, whereas those bereaved for a couple of decades did so rarely; this is consistent with findings of Boerner et al. (2005), who found that search for meaning decreased with time from 18 to 48 months postloss. Among those individuals who searched for meaning, there was no significant relationship between time since the loss and ability to find meaning; respondents found only a little meaning in the loss. Those individuals who had experienced the loss most recently showed some agreement that the loss was senseless and unfair, whereas those who had suffered the loss long ago expressed less agreement with the statement. Respondents showed moderate agreement with the statement that their spouse was better off dead, and this did not change with time. Taken together, these findings suggest that if individuals are going to resolve the loss of their spouse, they will do so relatively soon after the loss. Consistent with other researchers (Davis \& NolenHoeksema, 2001; Davis et al., 2000), we found that additional time does not appear to be helpful in reaching a state of resolution.

\section{Personal Growth}

Consistent with past research (e.g., Schaefer \& Moos, 2001; Thomas et al., 1998), our results provide support for the notion that the loss of a spouse can be accompanied by the perception of personal growth. With time, respondents experienced an increase in self-confidence. In addition, our bereaved respondents indicated that it was mostly true that they had become a stronger person as a result of the loss; this judgment did not change with time. In subsequent research, it will be important to delineate the process through which positive changes occur. In a heterogeneous sample of bereaved individuals, Gamino, Sewell, and Easterling (2000) found that personal growth was associated with having a chance to say goodbye, spirituality, spontaneous positive memories of the deceased, and finding something positive resulting from the loss. Positive changes may also stem from the successful assumption of challenging tasks that were formerly handled by the spouse (cf. Umberson, Wortman, \& Kessler, 1992).

\section{Strengths, Limitations, and Future Directions}

Because the present study was based on results from a large, national sample of the conjugally bereaved, it afforded a unique opportunity to assess the enduring consequences of such a loss However, because the present article has focused on a crosssectional comparison, we cannot draw firm conclusions about changes in recovery over time. Therefore, results suggesting that it took the bereaved as long as $50-70$ years to reach their lowest level on certain variables should be interpreted with caution. A potential problem with this cross-sectional data is that the length of time since widowhood may be confounded with other variables, such as whether the loss was untimely. We addressed this problem by controlling for variables that could influence whether the death was timely or not and that could therefore influence the course of adjustment to the loss and by controlling for the age of the participant and spouse, whether the death was expected or not, and whether the death was due to murder, accident, or suicide. In addition, it is possible that length of time widowed is confounded with cohort. Those who lost their spouse at one point in history (e.g., during World War II) might face different challenges than those who lost their spouse at another point in history (e.g., during the Vietnam War or during the mid-1980s). However, we tried to adjust for cohort effects statistically by controlling for age of the widowed. Another limitation of cross-sectional designs is that they do not lend themselves to the identification of preloss coping resources, such as social support or personality, that may influence the time course of recovery. The aforementioned issues can best be resolved through a prospective, longitudinal study that assesses individuals before and at several intervals following the loss of their spouse (e.g., Carr, Nesse, \& Wortman, 2006), with a focus on long-term recovery.

It is important to ask whether the design used in this study may have led respondents to exaggerate the length of time that they had thoughts, conversations, and feelings about their deceased spouse. We believe it is unlikely that our respondents exaggerated their reports because, as noted above, the study focused on a wide variety of life experiences and was not presented to respondents as a study on bereavement. One might consider the age of our data a limitation (as stated earlier, data were collected in 1986). However, given the consistency of our findings with the findings of more recent research, we do not think that the age of our data makes them unrepresentative.

Although we obtained an ethnically diverse sample, it was beyond the scope of the current study to examine ethnic differences in the trajectory of reactions to spousal loss. It was also beyond the scope of this study to examine potential moderating effects of other variables such as respondent's sex and remarriage after the loss. Finally, relatively little information was gathered regarding the cause of death. Consequently, we were unable to 
investigate how specific modes of death might influence the pattern of results. These are directions for future research.

\section{Conclusion}

Probably the most frequently asked questions about grief and mourning concern duration. Despite paying lip service to the notion that everyone's mourning is individual and that a complex of factors affect duration and course, almost everyone-from the mourner herself, to students, to caregivers, to media reporters-invariably returns to the question, "How long does mourning take?" (Rando, 1993, pp. 60-61)

The present results suggest that the grieving process following the loss of a long-term spouse can continue for many years. Even after decades have passed, it is common to have memories and conversations about one's spouse, to sometimes become sad and upset as a result, and at times to experience distress when reminders, such as the date of the spouse's death, are encountered. Hopefully, greater awareness of these findings can lead to better interventions and a more compassionate view of those who are attempting to come to terms with the loss of their spouse.

\section{References}

Aiken, L. R. (1991). Death, dying, and bereavement (2nd ed.). Boston: Allyn \& Bacon.

Arbuckle, N. W., \& de Vries, B. (1995). The long-term effects of later life spousal and parental bereavement on personal functioning. Gerontologist, 35, 637-647.

Archer, J. (1999). The nature of grief: The evolution and psychology of reactions to loss. London: Routledge.

Boerner, K., Wortman, C. B., \& Bonanno, G. A. (2005). Resilient or at risk? A 4-year study of older adults who initially showed high or low distress following conjugal loss. Journal of Gerontology: Series B. Psychological Sciences and Social Sciences, 60, 67-73.

Bonanno, G. A., Wortman, C. B., Lehman, D. R., Tweed, R. G., Haring, M., Sonnega, J., et al. (2002). Resilience to loss and chronic grief: A prospective study from preloss to 18-months postloss. Journal of Personality and Social Psychology, 83, 1150-1164.

Bonanno, G. A., Wortman, C. B., \& Nesse, R. M. (2004). Prospective patterns of resilience and maladjustment during widowhood. Psychology and Aging, 19, 260-271.

Bowlby, J. (1969). Attachment and loss: Vol. 1. Attachment. London: Hogarth.

Bowlby, J. (1973). Attachment and loss: Vol. 2. Separation-Anxiety and anger. New York: Basic Books.

Bowlby, J. (1980). Attachment and loss: Vol. 3. Loss-Sadness and depression. New York: Basic Books.

Calhoun, L. G., \& Tedeschi, R. G. (1990). Positive aspects of critical life problems: Recollections of grief. Omega: Journal of Death and Dying, $20,265-272$

Carnelley, K. B., Wortman, C. B., \& Kessler, R. C. (1999). The impact of widowhood on depression: Findings from a prospective survey. Psychological Medicine, 29, 1111-1123.

Carr, D., Nesse, R., \& Wortman, C. B. (Eds.). (2006). Spousal bereavement in late life. New York: Springer Publishing.

Carver, C. S., \& Scheier, M. F. (1982). Control theory: A useful conceptual framework for personality-social, clinical, and health psychology. Psychological Bulletin, 92, 111-135.

Cassidy, J., \& Shaver, P. R. (Eds.). (1999). Handbook of attachment: Theory, research, and clinical applications. New York: Guilford Press. Cohen, P., Cohen, J., Aiken, L. S., \& West, S. G. (1999). The problem of units and the circumstance of POMP. Multivariate Behavioral Research 34, 31-34.

Davis, C. G., \& Nolen-Hoeksema, S. (2001). Loss and meaning: How do people make sense of loss? American Behavioral Scientist, 44, 726-741.

Davis, C. G., Nolen-Hoeksema, S., \& Larson, J. (1998). Making sense of loss and benefiting from the experience: Two construals of meaning. Journal of Personality and Social Psychology, 75, 561-574.

Davis, C. G., Wortman, C. B., Lehman, D. R., \& Silver, R. C. (2000). Searching for meaning in loss: Are clinical assumptions correct? Death Studies, 24, 497-540.

Derogatis, L. R. (1983). SCL-90-R administration, scoring, and procedures manual II (2nd ed.). Towson, MD: Clinical Psychometric Research.

Field, N. P., Gal-Oz, E., \& Bonanno, G. A. (2003). Continuing bonds and adjustment at 5 years after the death of a spouse. Journal of Consulting and Clinical Psychology, 71, 110-117.

Field, N. P., Nichols, C., Holen, A., \& Horowitz, M. J. (1999). The relation of continuing attachment to adjustment in conjugal bereavement. Journal of Consulting and Clinical Psychology, 67, 212-218.

Frijda, N. H. (1986). The emotions. Cambridge, England: Cambridge University Press.

Frijda, N. H. (1988). The laws of emotion. American Psychologist, 43, 349-358.

Fry, P. S. (1998). Spousal loss in late life: A 1-year follow-up of perceived changes in life meaning and psychosocial functioning following bereavement. Journal of Personal and Interpersonal Loss, 3, 369-391.

Gamino, L. A., Sewell, K. W., \& Easterling, L. W. (2000). Scott and White Grief Study-Phase 2: Toward an adaptive model of grief. Death Studies, 24, 633-660.

Glick, I. O., Weiss, R. S., \& Parkes, C. M. (1974). The first year of bereavement. New York: Wiley.

Gorer, G. (1967). Death, grief and mourning. Garden City, NY: Anchor Books.

Hardt, D. V. (1978-1979). An investigation of the stages of bereavement Omega: Journal of Death and Dying, 9, 279-285.

House, J. S., Kessler, R. C., Herzog, A. R., Mero, R. P., Kinney, A. M., \& Breslow, M. J. (1990). Age, socioeconomic status, and health. Milbank Quarterly, 68, 383-411.

Ingram, K. M., Jones, D. A., \& Smith, N. G. (2001). Adjustment among people who have experienced AIDS-related multiple loss: The role of unsupportive social interactions, social support, and coping. Omega: Journal of Death and Dying, 43, 287-309.

Janoff-Bulman, R. (1992). Shattered assumptions: Towards a new psychology of trauma. New York: Free Press.

Janoff-Bulman, R., \& Frantz, C. M. (1997). The impact of trauma on meaning: From meaningless world to meaningful life. In M. Power \& C. R. Brewin (Eds.), The transformation of meaning in psychological therapies (pp. 91-106). Chichester, England: Wiley.

Kalton, G., \& Flores-Cervantes, I. (2003). Weighting methods. Journal of Official Statistics, 19, 81-97.

Klass, D., Silverman, P. R., \& Nickman, S. L. (1996). Continuing bonds: New understandings of grief. Washington, DC: Taylor \& Francis.

Klass, D., \& Walter, T. (2001). Process of grieving: How bonds are continued. In M. S. Stroebe, R. O. Hansson, W. Stroebe, \& H. Schuts (Eds.), Handbook of bereavement research: Consequences, coping, and care (pp. 431-448). Washington, DC: American Psychological Association.

Lazarus, R. S. (1991). Emotion and adaptation. New York: Oxford University Press.

Lazarus, R. S. (1999). Stress and emotion: A new synthesis. New York: Springer.

Lehman, D. R., Ellard, J. H., \& Wortman, C. B. (1986). Social support for the bereaved: Recipients' and providers' perspectives on what is helpful. Journal of Consulting and Clinical Psychology, 54, 438-446.

Lehman, D. R., Wortman, C. B., \& Williams, A. F. (1987). Long-term 
effects of losing a spouse or child in a motor vehicle crash. Journal of Personality and Social Psychology, 52, 218-231.

Lessler, J. T., \& Kalsbeek, W. D. (1992). Nonsampling errors in surveys. New York: Wiley.

Lieberman, M. (1996). Doors close, doors open: Windows, grieving and growing. New York: Putnam.

Lopata, H. Z. (1973). Self-identity in marriage and widowhood. Sociological Quarterly, 14, 407-418.

Marris, P. (1958). Widows and their families. London: Routledge \& Kegan Paul.

McGuigan, F. J. (1994). Biological psychology: A cybernetic science. Upper Saddle River, NJ: Prentice-Hall.

Miller, E. D., \& Omarzu, J. (1998). New directions in loss research. In J. Harvey (Ed.), Perspectives on loss: A sourcebook (pp. 3-20). Washington, DC: Taylor \& Francis.

Nolen-Hoeksema, S., Parker, L. E., \& Larson, J. (1994). Ruminative coping with depressed mood following loss. Journal of Personality and Social Psychology, 67, 92-104.

Parkes, C. M., \& Weiss, R. S. (1983). Recovery from bereavement. New York: Basic Books.

Rando, T. A. (1993). Treatment of complicated mourning. Champaign, IL: Research Press.

Rawlings, J. O., Pantula, S. G., \& Dickey, D. A. (1998). Applied regression analysis: A research tool (2nd ed.). New York: Springer-Verlag.

SAS Institute. (2004). SAS/STAT 9.1 user's guide. Cary, NC: Author.

Schaefer, J. A., \& Moos, R. H. (2001). Bereavement experiences and personal growth. In M. S. Stroebe, R. O. Hansson, W. Stroebe, \& H. Schut (Eds.), Handbook of bereavement research: Consequences, coping, and care (pp. 145-167). Washington, DC: American Psychological Association.

Shaver, P. R., \& Tancredy, C. M. (2001). Emotion, attachment, and bereavement: A conceptual commentary. In M. S. Stroebe, R. O. Hansson, W. Stroebe, \& H. Schut (Eds.), Handbook of bereavement research: Consequences, coping, and care (pp. 63-88). Washington, DC: American Psychological Association.

Singer, J. D., \& Willett, J. B. (2003). Applied longitudinal data analysis: Modeling change and event occurrence. New York: Oxford University Press.

Stephenson, J. S. (1985). Death, grief, and mourning. New York: Free Press.

Stroebe, M. S., Hansson, R. O., Stroebe, W., \& Schut, H. (2001a). Future directions for bereavement research. In M. S. Stroebe, R. O. Hansson, W. Stroebe, \& H. Schut (Eds.), Handbook of bereavement research: Consequences, coping, and care (pp. 741-766). Washington, DC: American Psychological Association.

Stroebe, M. S., Hansson, R. O., Stroebe, W., \& Schut, H. (Eds.). (2001b).
Handbook of bereavement research: Consequences, coping, and care. Washington, DC: American Psychological Association.

Stroebe, M. S., Hansson, R. O., Stroebe, W., \& Schut, H. (2001c). Introduction: Concepts and issues in contemporary research on bereavement. In M. S. Stroebe, R. O. Hansson, W. Stroebe, \& H. Schut (Eds.), Handbook of bereavement research: Consequences, coping, and care (pp. 3-22). Washington, DC: American Psychological Association.

Stroebe, M. S., \& Stroebe, W. (1989). Who participates in bereavement research? A review and empirical study. Omega: Journal of Death and Dying, 20, 1-29.

Stroebe, M. S., \& Stroebe, W. (1991). Does "grief work" work? Journal of Consulting and Clinical Psychology, 59, 479-482.

Stroebe, W., \& Schut, H. (2001). Models of coping with bereavement: A review. In M. S. Stroebe, R. O. Hansson, W. Stroebe, \& H. Schut (Eds.), Handbook of bereavement research: Consequences, coping, and care (pp. 375-403). Washington, DC: American Psychological Association.

Stroebe, W., \& Stroebe, M. S. (1987). Bereavement and health: The psychological and physical consequences of partner loss. New York: Cambridge University Press.

Thomas, L. E., DiGiulio, R. C., \& Sheehan, N. W. (1988). Identity loss and psychological crisis in widowhood: A re-evaluation. International Journal of Aging and Human Development, 26, 225-239.

Umberson, D., Wortman, C. B., \& Kessler, R. (1992). Widowhood and depression: Explaining gender differences in vulnerability. Journal of Health and Social Behavior, 33, 10-24.

United States Bureau of the Census. (1985). Statistical abstracts of the U.S., 1986. Washington, DC: Government Printing Office.

Weiss, R. S. (1988). Loss and recovery. Journal of Social Issues, 44, $37-52$.

Weiss, R. S. (2001). Grief, bonds, and relationships. In M. S. Stroebe, R. O. Hansson, W. Stroebe, \& H. Schut (Eds.), Handbook of bereavement research: Consequences, coping, and care (pp. 47-62). Washington, DC: American Psychological Association

Worden, J. W. (2002). Grief counseling and grief therapy (3rd ed.). New York: Springer Publishing Company.

Wortman, C. B., \& Silver, R. C. (1990). Successful mastery of bereavement and widowhood: A lifecourse perspective. In P. B. Baltes \& M. M. Baltes (Eds.), Successful aging: Perspectives from the behavioral sciences (pp. 225-264). New York: Cambridge University Press.

Zisook, S., Devaul, R. A., \& Click, M. A. (1982). Measuring symptoms of grief and bereavement. American Journal of Psychiatry, 139, 15901593.

Received September 28, 2005

Revision received January 18, 2006 Accepted January 30, 2006 